AperTO - Archivio Istituzionale Open Access dell'Università di Torino

\title{
Polymorphs and co-crystals of haloprogin: an antifungal agent
}

\section{This is the author's manuscript}

Original Citation:

Availability:

This version is available http://hdl.handle.net/2318/146438

since 2017-05-26T11:30:37Z

Published version:

DOI:10.1039/c4ce00367e

Terms of use:

Open Access

Anyone can freely access the full text of works made available as "Open Access". Works made available under a Creative Commons license can be used according to the terms and conditions of said license. Use of all other works requires consent of the right holder (author or publisher) if not exempted from copyright protection by the applicable law. 


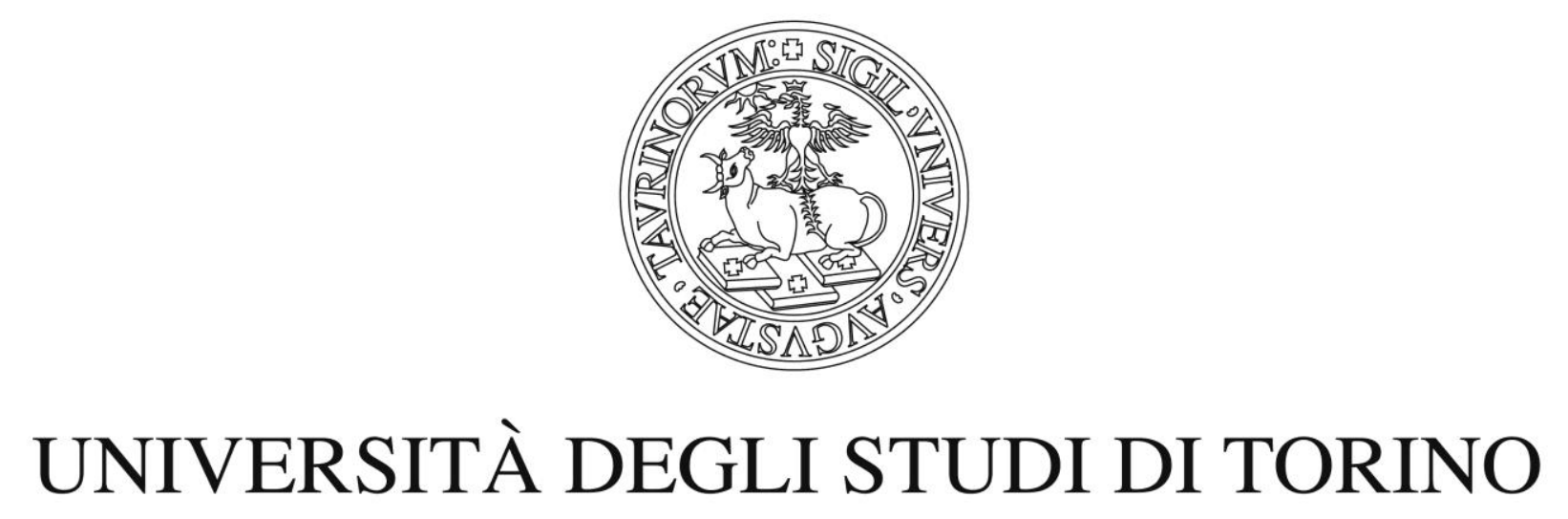

This is an author version of the contribution published on:

Questa è la versione dell'autore dell'opera:

CRYSTENGCOMM, v. 16 (2014), 5897-5904.

DOI: 10.1039/C4CE00367E

The definitive version is available at:

La versione definitiva è disponibile alla URL:

http://pubs.rsc.org/en/Content/ArticleLanding/2014/CE/c4ce00367e 


\title{
Polymorph and co-crystal screening of Haloprogin, an antifungal agent
}

\author{
Michele Baldrighi, ${ }^{a}$ Davide Bartesaghi, ${ }^{\mathrm{a}}$ Gabriella Cavallo, ${ }^{\mathrm{a}}$ Michele R. Chierotti, \\ Roberto Gobetto, ${ }^{\mathrm{b}}$ Pierangelo Metrangolo, ${ }^{* \mathrm{a}}$ Tullio Pilati, ${ }^{\mathrm{a}}$ Giuseppe Resnati, ${ }^{* \mathrm{a}}$ \\ and Giancarlo Terraneo* ${ }^{\text {a }}$
}

\begin{abstract}
Haloproginis a topical antifungal agent. Its structuredoes not contain any of the functional groups typically exploited in hydrogen bond based co-crystal design. On the other hand, its 1iodoalkyne moiety is nicely tailored to a crystal engineering strategy based on halogen bonding. Here we describe the formation of threepolymorphs of haloprogin and of threecocrystalsthat this active pharmaceutical ingredient forms with both neutral and ionic co-crystal formers. The halogen bond plays a major role in all of the six structures and the interaction is thus confirmed to be a valuable tool which may complement the hydrogen bond when polymorph and co-crystal screeningsare pursued.
\end{abstract}

\section{Introduction}

Polymorph and co-crystal screeningsareuseful strategies to find new solid forms of active pharmaceutical ingredients(APIs), in order to alter/improve their physical properties without changing their chemical identities or biological activities. ${ }^{1}$ Most commonly APIs have hydrogen bonding donor and acceptor groups that are involved in the binding of the co-crystal former (CCF), e.g., carboxylic acids and aromatic nitrogen atoms havebeen proven particularly reliable moieties in hydrogen bonding (HB) driven formation of API-CCF adducts. ${ }^{2}$ On the other hand, the design of pharmaceutical co-crystals involving APIs devoid of strong hydrogen bonddonor sitesisquite challenging.

Halogen atoms are frequently present in drugs molecules and we considered that they can be used to drive the formation of pharmaceutical co-crystals if the halogen bonding ${ }^{3}(\mathrm{XB})$ is used. Recently we demonstrated that the iodoalkyne moiety of an API can be successfully used to prepare halogen-bonded cocrystalswith improved physicochemical properties. ${ }^{4}$ In this paper we describe a further case where the same moiety drives the formation of co-crystals with neutral and anionic partners. More important, we describe how the iodoalkyne moiety can play an active role in the formation of different polymorphs of an API.

Haloprogin1(1,2,4-trichloro-5-[(3-iodoprop-2-yn-1yl)oxy]benzene) is the API of antimycotic topical drugswith brand names of Halotex ${ }^{\circledR}$, Mycanden ${ }^{\circledR}$, Mycilan ${ }^{\circledR}$ and Polik ${ }^{\circledR}$ (Scheme 1). ${ }^{5}$ No structures involving 1are reported in the
Cambridge Structural Database (CSD), ${ }^{6}$ consistent with the fact that it may represent a difficult challenge if a standard approach for polymorph and co-crystal formation is pursued since it does notcontain any of the functional groupstypically required for a HB-based strategy. ${ }^{1,2}$
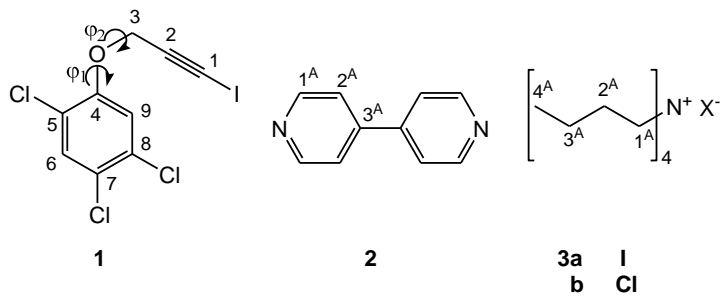

Scheme 1.Molecular structures of Haloprogin and of the used CCFs. The used atom labels are indicated for all structures. Torsion angles $\varphi_{1}$ and $\varphi_{2}$ are indicated with curved arrows.

On the other hand, an iodine atom bound to the $s p$ hybridisedcarbon atom displays a particularly anisotropic distribution of its electron density. ${ }^{7}$ A region of remarkably positive electrostatic potential, the so-called positive $\sigma$-hole, ${ }^{8}$ is present on the outermost surface of the iodine atom and along the extension of the C-I covalent bond.This specific feature makes the iodoalkynemoiety a very good $\mathrm{XB}$ donorsite. ${ }^{9,10} \mathrm{We}$ reasoned that the presence in 1 of one efficient XBdonor sitealong with the absence of strong HBdonor sites represents a unique opportunity to explore the obtainment of new cocrystals based on XB.In addition, the presence in 1of multiple electrondonor sites that may be involved in $\mathrm{XB}$, e.g., the 
chlorine atoms, the oxygen atom, and the $\pi$ electrons, may favour the obtainment of different polymorphs and allow for a quite rich structural landscape for the pure API.

Three polymorphs 1a, 1b, and 1cof haloprogin are described here.As far as co-crystals of 1are concerned, we obtained a neutral co-crystal 4 with 4,4'-bipyridine (2) and two ionic co-crystals 5aand 5bwith tetran-butylammonium iodide (3a) and chloride (3b). ${ }^{11}$ The studied CCFs were chosen in order to cover both neutral and anionic electron densitydonor sites, which are both well represented in the FDA-GRAS ${ }^{12}$ (Food and Drug Administration-Generally Recognized As Safe) list.All obtained solid forms of $\mathbf{1}$ (polymorphs and co-crystals) were fully characterized by using various analyticaltechniques, such as single-crystal and powder X-ray diffraction analyses, FT-IR, differential scanning calorimetry (DSC), and solid state (SS)NMR.

\section{Experimental Section}

\section{Materials}

Solvents and reagents were purchased from Sigma Aldrich at high purity grade and used without further purification. haloprogin was synthesized in two steps according to the procedure reported by Fellig et al. ${ }^{13}$ (see ESI). Solution NMR spectra were collected on a Bruker AV400 spectrometer. Single crystals of polymorphs $\mathbf{1 a}$ and $\mathbf{1 b}$ were obtained by slow evaporation methods. Single crystals of polymorphs $\mathbf{1 b}$ and 1c were obtained viaboth slow evaporation and sublimation.Cocrystalsof 4were obtained by slow evaporation methods. Mechanochemical synthesis of 5aand $\mathbf{5 b w a s}$ performed using a Retsch MM400 ball mill with $5.0 \mathrm{~mL}$ vessels, operating at 30 Hz. Correspondingsingle crystals were obtained by seeding quasi-saturated solutions of 1 and $3 \mathbf{a}$ aor $\mathbf{3 b}$, respectively (in the appropriate molar ratio) with the powders obtained from ball milling experiments.

Vibrational Spectroscopy. IR spectra were collected using a Nicolet Nexus FT-IR spectrometer equipped with Smart Endurance ATR device, and analysed using Omnic software v.7.3. Peak values are given in wavenumbers $\left(\mathrm{cm}^{-1}\right)$ upon automatic assignment.

Thermal Analysis.Melting points were collected using a Linkam Hot-Stage microscopy apparatus. Thermal analysis was performed on a Mettler Toledo DSC 823e differential scanning calorimeter.

X-ray Crystallography.A Bruker AXS D8 powder diffractometer was used for all X-ray powder (XRPD) measurements with experimental parameters are as follows: $\mathrm{Cu}-\mathrm{K} \alpha$ radiation $(\lambda=1.54056 \AA)$, scanning interval: $4-40^{\circ} 2 \theta$. Step size $0.016^{\circ}$, exposure time $1.5 \mathrm{~s} / \mathrm{step}$. Single crystal X-ray diffraction (XRD) data were collected on a Bruker AXS KAPPA-APEX II CCD diffractometer using Mo-K $\alpha$ radiation $(\lambda=0.71073 \AA)$. Data integration and reduction were performed using SaintPlus 6.01. ${ }^{14}$ Absorption correction was performed with a multi-scan method implemented in SADABS. ${ }^{15}$ Space groups were determined using XPREP implemented in APEX II suite. ${ }^{16}$ Structures were solved using SHELXS-97 (direct methods) and refined using SHELXL-97 ${ }^{17}$ (full-matrix least-squares on $\mathrm{F}^{2}$ ) contained in APEX II and WinGX v1.80.01software packages. ${ }^{18}$ All non-hydrogen atoms were refined anisotropically. Hydrogen atoms were placed in geometrically calculated positions and included in the refinement process using a riding model with isotropic thermal parameters. Analysis of crystal data and pictures were performed with Mercury $3.1 .{ }^{19}$ Crystal data are reported in Table 1 .

Solid state NMR.SSNMR measurements were run on a Bruker AVANCE II 400 instrument operating at 400.23, 100.65 and $40.55 \mathrm{MHz}$ for ${ }^{1} \mathrm{H},{ }^{13} \mathrm{C}$ and ${ }^{15} \mathrm{~N}$, respectively. ${ }^{13} \mathrm{C}$ and ${ }^{15} \mathrm{~N}$ CPMAS spectra were recorded at room temperature at the spinning speed of $12\left({ }^{13} \mathrm{C}\right)$ or $9 \mathrm{kHz}\left({ }^{15} \mathrm{~N}\right)$. Cylindrical $4 \mathrm{~mm}$ o.d. zirconia rotors with sample volume of $80 \mu \mathrm{L}$ were employed. A ramp cross-polarization pulse sequence was used with contact times of $5 \mathrm{~ms}$, a ${ }^{1} \mathrm{H} 90^{\circ}$ pulse of $3.30 \mu \mathrm{s}$, recycle delays of 10 $40 \mathrm{~s}$, and $512-4096\left({ }^{13} \mathrm{C}\right)$ or $1400-1600\left({ }^{15} \mathrm{~N}\right)$ transients. The two pulse phase modulation (TPPM) decoupling scheme was used with a frequency field of $75 \mathrm{kHz}$. Spectral editing experiments were performed by using a CPPISPI pulse sequence with a polarization inversion time of $65-85 \mu \mathrm{s}$ in order to obtain $\mathrm{CH}_{3}$ and $\mathrm{C}_{\mathrm{q}}$ positive, $\mathrm{CH}$ null, and $\mathrm{CH}_{2}$ negative. ${ }^{13} \mathrm{C}$ and ${ }^{15} \mathrm{~N}$ scales were calibrated with glycine $\left({ }^{13} \mathrm{C}\right.$ methylene signal at $43.86 \mathrm{ppm})$ and $\left(\mathrm{NH}_{4}\right)_{2} \mathrm{SO}_{4}\left({ }^{15} \mathrm{~N}\right.$ signal at $\delta=355.8$ ppm with respect to $\mathrm{CH}_{3} \mathrm{NO}_{2}$ ) as external standards. ${ }^{13} \mathrm{C}$ and ${ }^{15} \mathrm{~N}$ chemical shift assignment for pure reagents and for the cocrystals are in the SI.Atom labels used in SSNMR studies are reported in the Scheme 1. Spectral editing techniques were useful for unambiguous assignments. All ${ }^{13} \mathrm{C}$ and ${ }^{15} \mathrm{~N}$ chemical shifts with assignments are reported in the Table S1 in the ESI.

Conformational and computational analysis.The conformational comparison was performed overlapping the aromatic portions of the three polymorphs of1. Energy calculations were performed at MP2/6-311+G(d,p) level of theory within Spartan Software. ${ }^{20}$ The molecular geometry obtained by X-ray studies was used for these analysis.

\section{Preparation of polymorphs and co-crystals}

Synthesis of polymorph 1a:In a $2.5 \mathrm{~mL}$ glass vial, $10 \mathrm{mg}$ of $\mathbf{1}$ $(0.027 \mathrm{mmol})$ were dissolved in $1.5 \mathrm{~mL}$ of chloroform. The open vial was left in the hood at room temperature and after 17 hours clear colourless octahedral crystals of 1awere foundat the bottom of the vial,. M.p.: $111^{\circ}$ C. FTIR (selected bands): 2187, $1581,1472,1453,1232,1077,1028,866,724,681 \mathrm{~cm}^{-1}$.

Syntheses of polymorphs $1 \mathrm{~b}$ and 1c: In a $2.5 \mathrm{~mL}$ glass vial, $11.7 \mathrm{mg}$ of $1(0.032 \mathrm{mmol})$ were dissolved in $1.0 \mathrm{~mL}$ of chloroform, then a solution of sodium acetate $(2.9 \mathrm{mg}, 0.032$ $\mathrm{mmol})$ in methanol $(1.0 \mathrm{~mL})$ was stratified on top of the solution of 1 . The vial was capped and the solvents slowly evaporatedthrougha needle in the cap. 
Table 1. Crystallographic data for polymorphs 1a-c and co-crystals4 and 5a,b.

\begin{tabular}{|c|c|c|c|c|c|c|}
\hline & $1 \mathbf{a}$ & $1 \mathrm{~b}$ & 1c & 4 & $5 \mathbf{a}$ & $\mathbf{5 b}$ \\
\hline Chemical Formula & $\mathrm{C}_{9} \mathrm{H}_{4} \mathrm{Cl}_{3} \mathrm{IO}$ & $\mathrm{C}_{9} \mathrm{H}_{4} \mathrm{Cl}_{3} \mathrm{IO}$ & $\mathrm{C}_{9} \mathrm{H}_{4} \mathrm{Cl}_{3} \mathrm{IO}$ & $\mathrm{C}_{28} \mathrm{H}_{16} \mathrm{Cl}_{6} \mathrm{I}_{2} \mathrm{~N}_{2} \mathrm{O}_{2}$ & $\mathrm{C}_{34} \mathrm{H}_{44} \mathrm{Cl}_{6} \mathrm{I}_{3} \mathrm{NO}_{2}$ & $\mathrm{C}_{34} \mathrm{H}_{44} \mathrm{Cl}_{7} \mathrm{I}_{2} \mathrm{NO}_{2}$ \\
\hline Formula weight & 361.37 & 361.37 & 361.37 & 878.93 & 1092.10 & 1000.65 \\
\hline Temperature K & 295 & 296 & 296 & 296 & 296 & 103 \\
\hline Crystal system & Monoclinic & Triclinic & Monoclinic & Triclinic & Orthorhombic & Orthorhombic \\
\hline Space group & $C 2 / c$ & $P-1$ & $C 2 / c$ & $P-1$ & $P b c n$ & $P b c n$ \\
\hline$a(\AA)$ & $22.173(2)$ & $4.2659(6)$ & $31.100(5)$ & $7.4865(14)$ & $8.9174(9)$ & $8.557(2)$ \\
\hline$b(\AA)$ & $7.6870(7)$ & $10.4936(14)$ & $5.3807(7)$ & $13.522(3)$ & $15.2187(12)$ & $14.816(3)$ \\
\hline$c(\AA)$ & $13.8308(13)$ & $13.3814(16)$ & $13.861(2)$ & $17.240(3)$ & $31.429(3)$ & $31.189(6)$ \\
\hline$\alpha\left(^{\circ}\right)$ & 90.00 & $108.226(12)$ & 90 & $67.769(9)$ & 90.00 & 90.00 \\
\hline$\beta\left(^{\circ}\right)$ & $109.181(4)$ & $93.893(12)$ & $107.050(5)$ & $81.362(9)$ & 90.00 & 90.00 \\
\hline$\left.x^{\circ}\right)$ & 90.00 & $90.291(12)$ & 90 & $79.166(9)$ & 90.00 & 90.00 \\
\hline Volume $\left(\AA^{3}\right)$ & $2226.5(4)$ & $567.43(13)$ & $2217.5(6)$ & $1580.7(5)$ & $4265.3(7)$ & 3954.2(14) \\
\hline$Z$ & 8 & 2 & 8 & 2 & 4 & 4 \\
\hline Density $\left(\mathrm{gcm}^{-3}\right)$ & 2.156 & 2.115 & 2.159 & 1.847 & 1.701 & 1.681 \\
\hline$\mu\left(\mathrm{mm}^{-1}\right)$ & 3.588 & 3.490 & 3.572 & 2.526 & 2.603 & 2.095 \\
\hline$F(000)$ & 1360 & 340 & 1352 & 844 & 2128 & 1984 \\
\hline $\mathrm{ABS}_{\min }, \mathrm{T}_{\max }$ & $0.6548,0.7465$ & $0.5823,0.7452$ & - & $0.4510,0.9125$ & $0.3943,0.5199$ & $0.5999,0.7458$ \\
\hline$\theta_{\min , \max }\left({ }^{\circ}\right)$ & $1.94,32.86$ & $1.61,27.75$ & $2.74,24.99$ & $1.28,32.32$ & $2.59,29.25$ & $2.72,38.01$ \\
\hline$h_{\min , \max }$ & $-32,25$ & $-5,5$ & $-31,32$ & $-10,10$ & $-12,12$ & $-13,14$ \\
\hline$k_{\min , \max }$ & $-10,11$ & $-13,13$ & $-6,6$ & $-20,16$ & $-20,20$ & $-25,23$ \\
\hline$l_{\min , \max }$ & $-21,21$ & $-16,16$ & $-16,9$ & $-24,24$ & $-42,43$ & $-51,51$ \\
\hline No. of reflections. & 15765 & 13209 & 2364 & 30410 & 61875 & 91960 \\
\hline No. unique reflections. & 3779 & 2461 & 1634 & 9602 & 5811 & 10012 \\
\hline No of parameter & 127 & 127 & 128 & 361 & 211 & 211 \\
\hline$R_{\text {_all }}, R_{\text {_obs }}$ & $0.0452,0.0366$ & $0.0385,0.0314$ & $0.1436,0.1236$ & $0.0546,0.0303$ & $0.0524,0.0341$ & $0.0405,0.0267$ \\
\hline$w R_{\text {2_all }}, w R_{\text {2_obs }}$ & $0.1082,0.1035$ & $0.0785,0.0737$ & $0.2992,0.2744$ & $0.0733,0.0633$ & $0.0869,0.0736$ & $0.0537,0.0497$ \\
\hline$\Delta \rho_{\max , \min }\left(\mathrm{e}^{-3}\right)$ & $-1.001,1.126$ & $-0.993,0.609$ & $-1.631,4.982$ & $-0.482,0.713$ & $-0.858,1.013$ & $-1.766,1.237$ \\
\hline G.o.F & 1.058 & 1.059 & 1.044 & 1.004 & 1.079 & 1.086 \\
\hline CCDC & 986303 & 986304 & 986305 & 986300 & 986302 & 986301 \\
\hline
\end{tabular}

After two days, needles of $\mathbf{1 b}$ and few small needles of 1cappeared along with many crystals of $1 \mathbf{a}$. 1a,1b, and 1cwere separated by visual inspection. M.p.s: $1 \mathbf{b}, 113^{\circ} \mathrm{C} ; \mathbf{1 c}, 91^{\circ} \mathrm{C}$; FTIR of 1b (selected bands): 3100, 2928, 2186, 1582, 1471, $1335,1233,1077,867,725 \mathrm{~cm}^{-1}$.

Synthesis of polymorphs1b and 1cby sublimation:The crude powdered $1 \mathrm{a}$ was sublimated at $80^{\circ} \mathrm{C}$ under vacuum $(\mathrm{P} \sim 20$ mbar). After 10 hours, a mixture of 1 band 1ccrystals were collected on a glass slide fixed to the water cooled condenser.The 1c crystals completely transformed into polycrystalline1aon standing at room temperature.

Synthesis of 4 (Haloprogin:bipyridyl,2:1ratio):In a $10 \mathrm{~mL}$ glass vial $400 \mathrm{mg}(1.106 \mathrm{mmol})$ of $\mathbf{1}$ were dissolved in $5.0 \mathrm{~mL}$ of dichloromethane, then a solution of 4,4'-bipyridyl $(84.7 \mathrm{mg}$, $0.553 \mathrm{mmol}$ ) in $2 .=\mathrm{mL}$ of dichloromethane was added. The open vial was left in the hood at room temperature. After three days, several yellowish prisms appeared at the bottom and on the walls of the vial. M.p.: $118^{\circ} \mathrm{C}$; FTIR (selected bands): 3096 , 2178, 1620, 1473, 1336, 1078, 1026, 801, 723, $614 \mathrm{~cm}^{-1}$.

Synthesis of 5a (Haloprogin:tetra $n$-butylammonium iodide,2:1ratio): $200 \mathrm{mg}$ of $\mathbf{1}(0.553 \mathrm{mmol})$ and $102 \mathrm{mg}$ of tetran-butylammonium iodide $(0.277 \mathrm{mmol})$ were ground together in a high-speed ball milling apparatus for 30min at $30 \mathrm{~Hz}$. Powders were collected and analyzed by FTIR, XRPD, and DSC. M.p.: $67^{\circ}$ C; FTIR (selected bands): 2957, 2872, 2180, 1585, 1473, 1377, 1240, 1077, 1033, $764 \mathrm{~cm}^{-1}$. Single crystals were obtained by seeding a quasi-saturated solution of $\mathbf{1}$ and 3a (2:1 molar ratio) in methanol with the finely ground powders obtained from the solid-state synthesis and then allowing for the slow evaporation of thesolvent at room temperature.

Synthesis of $\mathbf{5 b}$ (Haloprogin:tetra $\boldsymbol{n}$-butylammonium chloride,2:1ratio):500 $\mathrm{mg}$ of $\mathbf{1}(1.383 \mathrm{mmol})$ and $192 \mathrm{mg}$ of tetran-butylammonium chloride $(0.692 \mathrm{mmol})$ were ground together in a high-speed ball milling apparatus for 30min at $30 \mathrm{~Hz}$. The resulting powder was collected and analyzed by FTIR, XRPD, and DSC. M.p.: $82^{\circ} \mathrm{C}$; FTIR (selected bands): 2960, 2872, 2176, 1474, 1350, 1241, 1078, 1031, 875, $681 \mathrm{~cm}^{-}$ 1 . Single crystals were obtained by seeding a quasi-saturated solution of $\mathbf{1}$ and $\mathbf{3 b}$ (2:1 molar ratio) in methanol with the finely ground powder obtained from the solid-state synthesis and then allowing for the slow evaporation of the solvent at room temperature. 


\section{Results and discussion}

\section{Polymorph screening}

The crystal structure of $\mathbf{1}$ is unknown andit was expected that different polymorphs may be formed as several electron-donor sites, i.e., oxygen, chlorine, and $\pi$-systems, can accept $\mathrm{XB}$ from the iodoalkyne moiety. Severalcrystallization conditions were thus employed in order to explore the structural landscape of $\mathbf{1}$ and obtain different polymorphic forms.

Slow evaporation of a chloroform solution of $\mathbf{1}$ afforded polymorph 1a as octahedral crystals with m.p. of $111^{\circ} \mathrm{C}$. The single crystal X-ray analysis revealed that XBplays a role in the structure of $\mathbf{1 a}$ (Figure 1, top). In fact, the iodine atom functions as theXB-donor andforms a short contact with the $\pi$-electron density of the triple bond, working as the XBacceptor, of another molecule of haloprogin (symmetry operation 1/2$x, 1 / 2+y, 1 / 2-z)$. An infinite halogen-bonded chain is formedand propagates parallel to the crystallographic $b$ axis (Figure 1, mid). The supramolecular chains of haloprogin molecules display a zig-zag arrangement with the $\mathrm{I} 1 \cdots \mathrm{C}^{*} \cdots \mathrm{I} 1^{i}(i=1 / 2-$ $\mathrm{x}, 1 / 2+\mathrm{y}, 1 / 2-\mathrm{z})$ angle of $85.2^{\circ}, \mathrm{C}^{*}$ being the centroid of the triple bond. The $\mathrm{C}^{*} \cdots \mathrm{I} 1^{i}$ distance is $3.556(3) \AA\left(\mathrm{C} 2 \cdots \mathrm{I} 1^{i}\right.$ and C1 $\cdots$ I $1^{i}$ distances are 3.560(3) $\AA$ and 3.649(3) $\AA$, respectively), while the $\mathrm{C} 1-\mathrm{I} 1 \cdots \mathrm{C}^{*}$ angle is $148.3(2)^{\circ}$. It should be noted here that these geometrical parameters are slightly longer and less linear than those found in similar supramolecular synthons reported in the $\mathrm{CSD}$ (see ESI). ${ }^{21} \pi-\pi$ Stacking interactions between couples of anti-parallel aromatic rings are also present with a separation of the rings centroids of $3.831 \AA$ (Figure 1 , bottom).

Looking for other polymorphic forms of $\mathbf{1}$, several organic solvents and their combinations were explored. All experiments resulted in the exclusive formation of polymorph1a (see ESI) but when the ionic strength of the crystallization medium was drastically increased. In fact, when a chloroform solution of haloprogin was allowed to slowly diffuse into a saturated methanol solution of sodium acetate and the resulting solvents mixture was slowly evaporated at room temperature (two days), some crystals oftwo newpolymorphs, 1band1c, were obtained along with massive quantities of 1a. Specifically, some rectangular needle-like crystals (1b, m.p.: $\left.113^{\circ} \mathrm{C}\right)$ and a few long and tiny needles (1c, m.p. $91{ }^{\circ} \mathrm{C}$ ) were formed together with larger amounts of $\mathbf{1 a}$ (octahedral crystals, m.p. $111^{\circ} \mathrm{C}$ ). Interestingly, a similar mixed phase was also obtained by sublimating powdersof $\mathbf{1 a}$.

Single-crystal X-ray analyses demonstrated that 1a, 1b, and 1c present quite different patterns of XBs. In polymorph $\mathbf{1 b}$, the iodine atom works as XB donor sites, similar to $\mathbf{1 a}$, but the $\mathrm{XB}$ acceptor site is the para positioned chlorine atom of its centrosymmetric molecule which present the same XB pattern and a cyclic dimer is formed (Figure 2, top left). The $\mathrm{I} \cdots \mathrm{Cl}$ distance is $3.633(2) \AA(0.97 \%$ of the sum of van der Waals $\operatorname{radii}^{22}(\mathrm{svdWr})$ of involved atoms) and the $\mathrm{C}-\mathrm{I} \cdots \mathrm{Cl}$ and $\mathrm{I} \cdots \mathrm{Cl}-$ Canglesare $171.71(9)^{\circ}$, and $103.67(11)^{\circ}$, respectively.
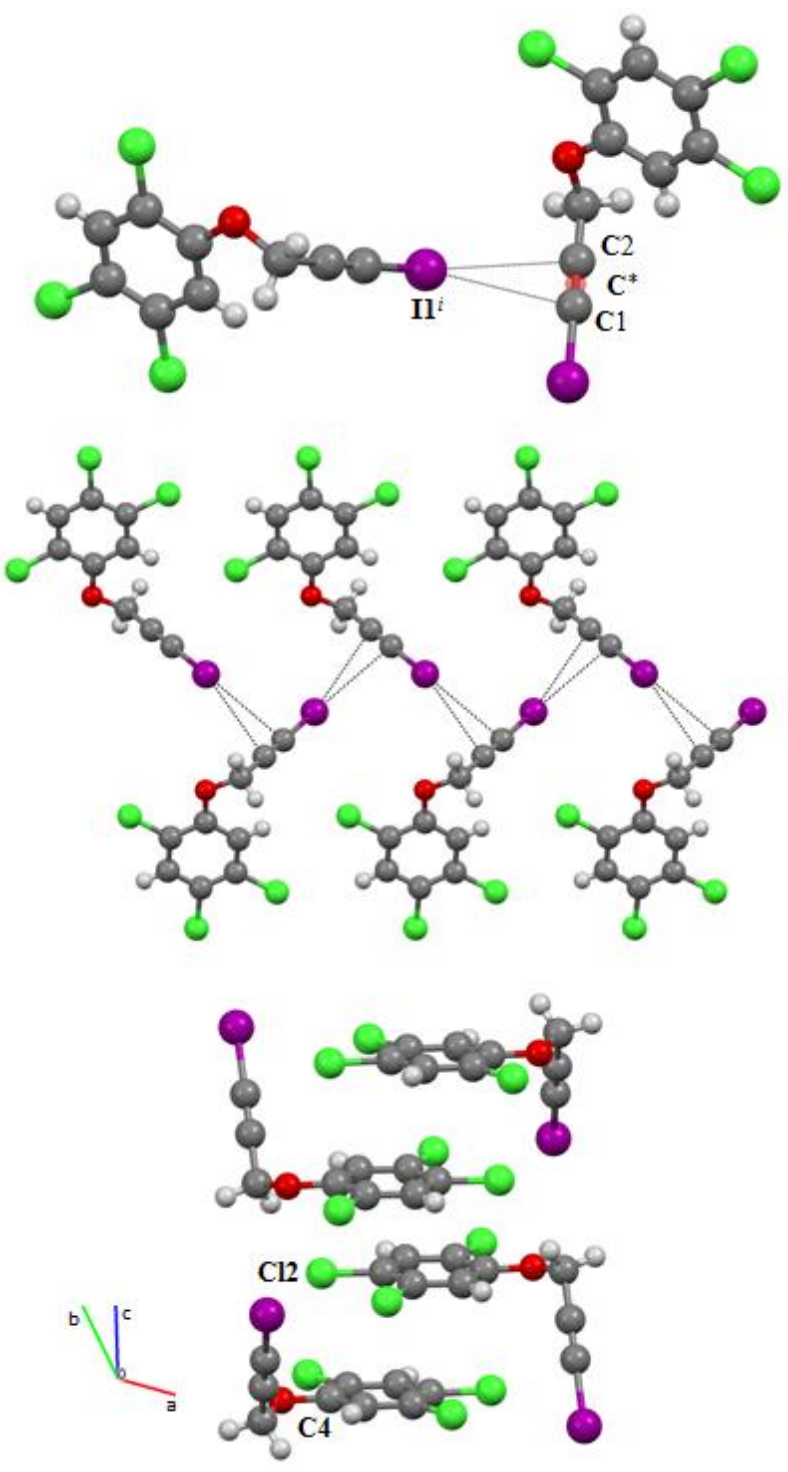

Figure 1.Top:XBs between the iodine atom and the $\pi$ electrons of the triple bond in 1a. Mid: supramolecular zig-zag and halogen-bonded chain. Bottom: antiparallel $\pi-\pi$ stacking of $\mathbf{1}$ molecules involving the aromatic portions of two haloprogin molecules. XBs are black dotted lines. The triple bond centroid is indicated with a transparent red dot and the symbol $\mathrm{C}^{*}$.

Colour code: carbon, grey; hydrogen, light grey; oxygen, red; chlorine, green; iodine, purple. 


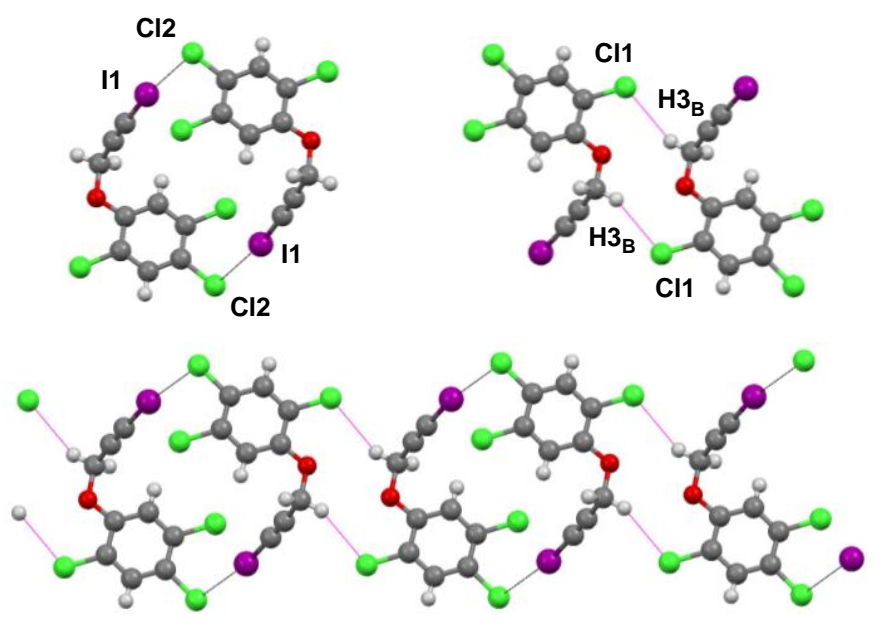

Figure 2.Structural motifs present in polymorph 1b. "Head to tail" dimersoriginated by two I $\cdots \mathrm{Cl}$ XBs (top left, XBs as black lines) and two

$\mathrm{H} \cdots \mathrm{Cl} \mathrm{HBs}$ (top right, $\mathrm{HBs}$ as magenta lines). Infinite chain formed by halogen and hydrogen bonds. Label for equivalent position: $i$ (1-x, 1-y, 2-z) and $i i(1-\mathrm{x}, 1-\mathrm{y}, 1-\mathrm{z})$. Colour code of atoms as in Figure 1.

These two angles are perfectly in line with the anisotropic electrostatic potentials around halogen atoms, with the iodine atom interacting through its electron poor $\sigma$-hole and the chlorine atom through its electron rich equatorial belt. Some other short contacts are present in this polymorph. Two HBs bridge two adjacent haloprogin molecules by connecting the chlorine atom of one molecule to one of the methylene hydrogens of another molecule $\left(\mathrm{H} 3_{\mathrm{B}} \cdots \mathrm{Cl} 1\right.$ distance is $2.82 \AA$, $0.96 \%$ of svdWr of involved atoms) and hydrogen-bonded cyclic dimers are formed (Figure 2, top right). Halogen and hydrogen-bonded cyclic dimers are connected in the overall crystal packing of polymorph $\mathbf{1 b a n d}$ produce ribbons extending along the $c$-axis (Figure 2, bottom).

It seemsthat crystalsof polymorph 1care quite unstableas, at room temperature, theyconvert into a powder sample of 1a. As a consequence, the collection of a complete crystallographic data set was not possible but the obtained data were enough to refine the crystal structure and have essential structural information (Table 1).Similar to polymorphs $\mathbf{1 a}$ and $\mathbf{1 b}$,also the crystal structure of 1cpresentsXBs whichare here the only noncovalent interactions below the svdWrof involved atoms. The iodine atom functions as a bifurcated XBdonor and interactsboth with the oxygen atom and with the chlorine atom ortho to the propargyl ether moiety(Figure 3, left). The $\mathrm{I} 1 \cdots \mathrm{Cl} 1{ }^{i i}(\grave{\imath} \mathrm{l}=1-\mathrm{x} .1+\mathrm{y}, 1 / 2-\mathrm{z})$ distance is $3.442(4) \AA$ (0.92the svdWr of involved atoms) and the $\mathrm{C} 1-\mathrm{I} 1 \cdots \mathrm{Cl} 1^{\mathrm{ii}}$ angle is $168.8(3)^{\circ}$, while the $\mathrm{I} 1 \cdots \mathrm{O} 1^{i i}$ distance is $3.448(10) \AA(0.98$ the svdWr of interacting atoms) and the $\mathrm{C} 1-\mathrm{I} 1 \cdots \mathrm{O} 1^{i i}$ angle is $141.7(4)^{\circ}$. These geometrical parameters closely resemble thosereported in the literaturefor bifurcated $\mathrm{XBs}^{23}$ where one $\mathrm{XB}$ contact is commonly shorter and more linear than the other. The propagation of this XB synthon results in infinite helical chains that develop along the $b$ axis(Figure 3, right).
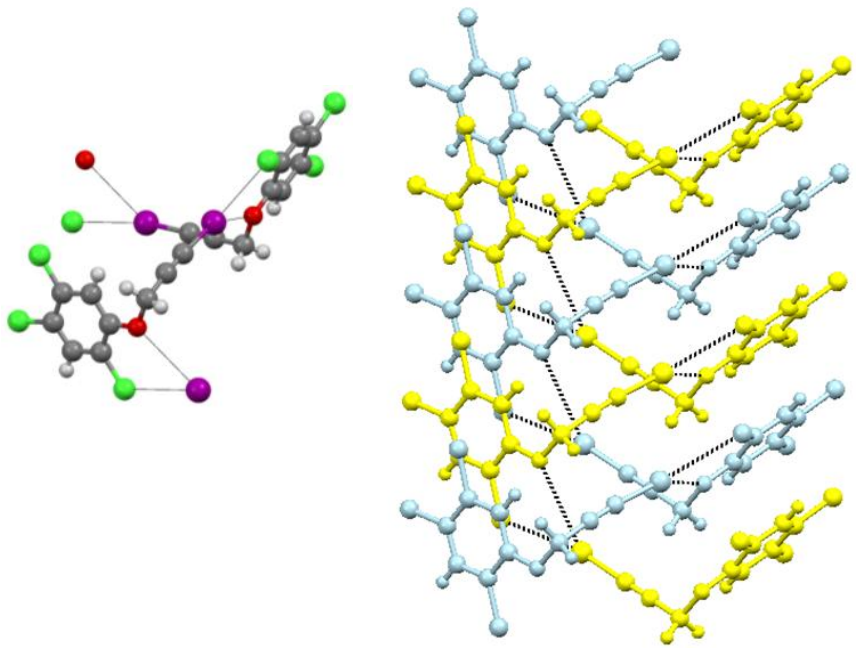

Figure 3.Left: the bifurcated XB motifpresent in 1c. Colour code as in Figure 1.Right: two helical chains, two different colours are used to highlight the different rotation of the chains.

Computational studies provided interesting pieces of information on the relative stabilities of the conformations adopted by molecule $\mathbf{1}$ in the three polymorphs. 1Hasfew degrees of conformational freedom which can be identified by the two torsion angles $\varphi_{1}(\mathrm{C} 3-\mathrm{O} 1-\mathrm{C} 4-\mathrm{C} 5)$ and $\varphi_{2}(\mathrm{C} 2-\mathrm{C} 3-\mathrm{O} 1-\mathrm{C} 4)$ (Scheme 1). The superposition of the aromatic rings of molecules 1in the conformations adopted in the three obtained polymorphs shows how in $\mathbf{1 a}$ and $\mathbf{1 b}$ the molecular geometry is almost identical with the two torsion angles that are very similar each other (Figure 4, left).

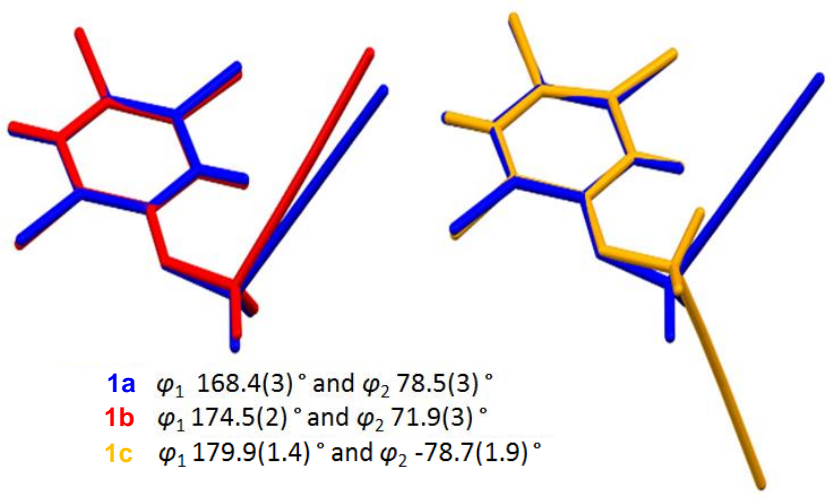

Figure 4.Comparison of the molecule conformations in the three polymorphs 1a-c. The torsion angles $\varphi_{1}$ and $\varphi_{2}$ are reported. Colour code: 1a, blue,1b, red, and 1c, yellow.

On the contrary, the haloprogin molecule in the polymorph 1c adopts a quite different conformation as shown in the Figure 4, right. Single point calculations (MP2/6-311+G(d,p)) on the X-ray molecular structures of the three polymorphsof haloprogin revealed that the conformation adopted in $\mathbf{1 a}$ is the most stable $(2.5 \mathrm{~kJ} / \mathrm{mol}$ more stable than $1 \mathbf{b})$ while the 
conformation of $\mathbf{1 c}$ is the least stable $(17.1 \mathrm{~kJ} / \mathrm{mol}$ less stable than 1a).

These calculations and the similarity of the respective melting points, may suggest that polymorphs1a and $\mathbf{1 b}$ are energetically similar although their intermolecular networksare different.The form $1 \mathrm{a}$ is quasi-exclusively obtained in the crystallization experiments and this may suggest that, in spite of the fact that inany haloprogin molecule there are three chlorine atoms versus one triple bond, the $\mathrm{I} \cdots \pi$ synthon is more favouredthan the $\mathrm{I} \cdots \mathrm{Cl}$ one. Definitely, the polymorph $\mathbf{1 c}$ is the least stable in the conditions used, as demonstrated by the small obtainable amount and by the fact that it converts into 1a with time at room temperature.

\section{Co-crystal screening}

The iodoalkynyl moiety being a robust $\mathrm{XB}$ donor, ${ }^{7-10}$ we have investigated the formation of co-crystals involving 1andboth neutral and anionic electron density donor partners. Here wedescribe the adducts $\mathbf{4}$ and $\mathbf{5 a}, \mathbf{b}$ obtained when 4,4'bipyridine (2) andtetrabutylammonium iodide (3a) or chloride (3b) are used as XB acceptors.

4 Was obtained by slow evaporation of a 2:1 mixture of the two starting materials 1 and 2 dissolved in methanol.The DSC thermogram suggested the formation of a new supramolecular entity since it showed a singleand sharp melting endotherm at $118{ }^{\circ} \mathrm{C}$, i.e., higher than the melting points of the starting compounds (2m.p.: 109-112 ${ }^{\circ} \mathrm{C}$ ).FTIR analysis confirmed that the supramolecular adduct formation involves the iodoalkynyl group, since the stretching band of the $\mathrm{C} \equiv \mathrm{C}$ bond is at $2187 \mathrm{~cm}^{-}$ ${ }^{1}$ in 1 aand at $2178 \mathrm{~cm}^{-1}$ in the adduct 4 .This red shiftclearly indicatesthat the iodine atom is halogen-bonded to a strong electron density-donor site. ${ }^{4}$

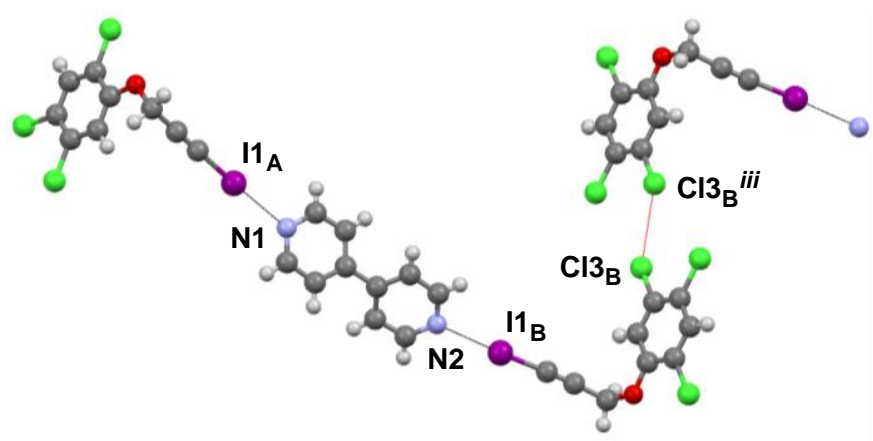

Figure 5.XBs(black dotted lines) and type I chlorine-chlorine interactions (red dotted lines) in the co-crystal 4. Label for equivalent position: iii(-x, 1$\mathrm{y},-\mathrm{z})$. Colour code: blue, nitrogen; other colours as in Figure 1.

The single crystal XRD analysis confirmed the formation of a 2:1 complex in which the molecule of $\mathbf{2}$ functions as a ditopic $\mathrm{XB}$ acceptor and interacts at either endings with two distinct molecules of 1thanks to I $\cdots \mathrm{N}$ XBs (Figure 5). The asymmetric unit is composed by two almost identical but independent $\mathrm{XB}$ donor molecules bound to the same bipyridine unit. Both the $\mathrm{XBs}$ are extremely short, linear, and similar in their geometrical parameters. I $\cdots \mathrm{N}$ Distances are 2.813(3) $\AA$ for I1 A $\cdots \mathrm{N} 1$ and $2.889(3) \AA$ for $\mathrm{I} 1 \mathrm{~B} \cdots \mathrm{N} 2$ (around $80 \%$ reduction of the svdWr of the interacting atoms) and angles $\mathrm{C} 1 \mathrm{~A}-\mathrm{I} 1 \mathrm{~A} \cdots \mathrm{N} 1$ and $\mathrm{C} 1 \mathrm{~B}-$ $\mathrm{I} 1 \mathrm{~B} \cdots \mathrm{N} 2$ are $177.95(10)^{\circ}$ and $177.84(10)^{\circ}$, respectively.

The crystal lattice of the 4adduct is also stabilised by other noncovalent interactions, most relevant the type-I halogenhalogen contacts occurring between two chlorine atoms $\left[\mathrm{Cl} 3 \mathrm{~B} \cdots \mathrm{Cl} 3 \mathrm{~B}^{i i i} \quad(i i i=-\mathrm{x}, 1-\mathrm{y}, 1-\mathrm{z})\right.$, distance $3.320(2) \quad \AA \quad$ and $\mathrm{C} 8 \mathrm{~B}-\mathrm{Cl} 3 \mathrm{~B} \cdots \mathrm{Cl} 3^{i i i}$ angle $\left.127.77(10)^{\circ}\right]$ and the $\pi-\pi$ stacking between aromatic rings (with a rings centroids separations of $3.597 \AA ̊$ ).

The synthesis of co-crystals of 5a,bwas carried out viamechanochemical reactions between $\mathbf{1}$ and ammonium halides 3a,b. Halide anions can work as polydentate XB acceptors and the number of formed interactions varies from one system to the other. DSC titration methods wereused to determine the preferred pairing ratiosbetween 1and3a,b. DSC analyses of 1:1 and 3:1 mixtures of $\mathbf{1}$ and 3aboth showed multiple endothermicpeaks.A new peak at $67{ }^{\circ} \mathrm{C}$, mismatching the starting components, was shown byboth mixture along with the melting of pure $3 \mathbf{a}$ (at $141{ }^{\circ} \mathrm{C}$ ) in the $1: 1$ mixture and of pure 1a (at $111^{\circ} \mathrm{C}$ ) inthe $3: 1$ mixture. This was suggesting that some excess starting component was present in both cases and that the preferred 1:3a pairing ratio in 5ais 2:1. Indeed, a mixture with this exact composition showed a single endothermic peak at $67{ }^{\circ} \mathrm{C}$.A similar DSC analysis revealed that also the pairing ratio for the complex $5 \mathbf{b}$ (m.p.: $83^{\circ} \mathrm{C}$ ) was 2:1.

FTIR spectroscopy on these halogen-bonded ionic cocrystals showed red-shifted triple bond stretching modes from $2187 \mathrm{~cm}^{-1}$ in pure 1 ato $2180 \mathrm{~cm}^{-1}$ in $\mathbf{5}$ aandto $2175 \mathrm{~cm}^{-1}$ in $\mathbf{5 b}$, suggesting the involvement of the iodoalkynyl fragment in the co-crystalsformation. The observed red-shiftstrend is also consistent with the chloride anion being a better XBacceptor than the iodide anion.

Very fewgood-quality single crystals of 5aand 5bwere obtained by adding finely ground powders of the complexes obtained in the mechanochemical syntheses toquasi-saturated methanolsolutions of the starting compounds (2:1 molar ratio). Their single crystal structure determination confirmed the formation of a new supramolecular adduct composed by two molecules of haloprogin and one molecule of ammonium halide.

The asymmetric unit of $\mathbf{5 a}$ iscomprisedby one molecule of 1 and half molecule of 3awhich lies on a twofold axis. The complex is assembled thanks to strong XBs occurring between the iodine atom of 1 and the iodide anionof the organic salt, which behaves ad a bidentate XBacceptor(Figure 6,left). The distance between the XBdonor and acceptor is 3.3977(4) $\AA$ ( $82 \%$ reduction of the svdWr of $\mathrm{I}$ and the Pauling ionic radius of $\mathrm{I}^{-}$) and the $\mathrm{C} 1-\mathrm{I} 1 \cdots \mathrm{I} 2$ angle 

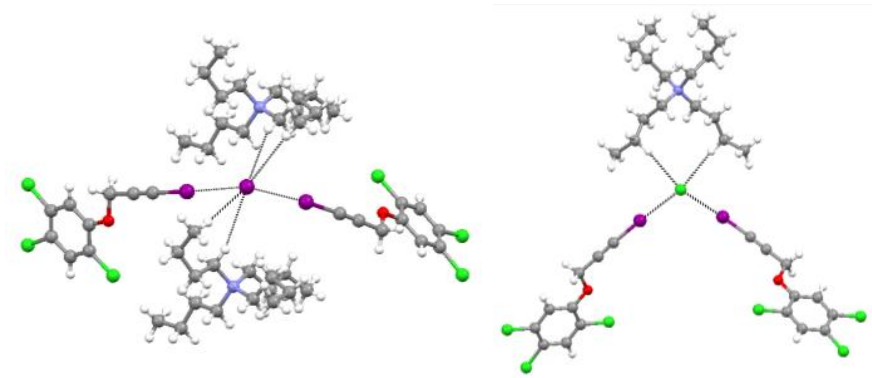

Figure 6.Bonding pattern around halide anions in the cocrystals 5a (left) and $\mathbf{5 b}$ (right). XBs and HBs are pictured as black dotted lines. In both $\mathbf{5 a}$ and $\mathbf{5 b}$ the $\mathrm{N}$ atom of the tetra n-butylammonium cation lies on a twofold axis. Colour code as in Figure 1.

is $175.73(12)^{\circ}$, both these values indicating the occurrence of a strong XB. The halide coordination sphere is completed by four $\mathrm{HB}$ contacts with $\mathrm{H}$ atoms belonging to the cation alkyl chains.

The crystal structure of $\mathbf{5 b}$ (Figure 6,right)is similar to $\mathbf{5 a}$. The chloride ion is halogen-bonded to iodineatom with a I1 $\cdots \mathrm{Cl} 4$ distance of $3.0427(5) \AA$ ( $80 \%$ reduction of the svdWr of I and the Pauling ionic radius of $\mathrm{Cl}^{-}$) and $\mathrm{C} 1-\mathrm{I} 1 \cdots \mathrm{Cl}^{-}$angle of $176.00(4)^{\circ}$ (Figure 6,right). This remarkably short distance confirms that the $\mathrm{C}-\mathrm{I} \cdots \mathrm{Cl}^{-}$synthon is stronger that the $\mathrm{C}-\mathrm{I} \cdots \mathrm{I}^{-}$one, in nice agreement with the differences in melting point and red-shift of triple bond stretching modesin FTIR spectra. In this case too, the halide anioncoordination sphere is completed by HB interactions involving the cation alkyl chains, but only two such interactions are present.

\section{Solid-State NMR studies}

Further characterization of the bulk materials was performed by multinuclear Solid-State NMR studies (SSNMR). Different from $\mathrm{HB},{ }^{24,25}$ only in recent years SSNMR has been applied to investigate $\mathrm{XB} .{ }^{26}$ This hasbeen done mainly by analysing directly involved nuclei such as ${ }^{19} \mathrm{~F},{ }^{14 / 15} \mathrm{~N},{ }^{35} \mathrm{Cl},{ }^{81} \mathrm{Br}$, and ${ }^{127} \mathrm{I},{ }^{27}$ but also neighbouring atoms have been considered. ${ }^{28}$ For instance, it was shown that ${ }^{13} \mathrm{C}$ resonances of halogen-bonded carbon atoms are broadened or even split due to a $2^{\text {nd }}$ order effect of dipolar coupling to the quadrupolar ${ }^{35 / 37} \mathrm{Cl}$ (both spin $3 / 2$ ) or ${ }^{127} \mathrm{I}$ ( spin 5/2) nuclei, ${ }^{29}$ thus confirming the proposed assignment for these signals.

Owing to the intrinsic difficulty of achieving relevant quantities of $\mathbf{1 b}$ and $\mathbf{1 c}$ polymorphs, here we report only the SSNMR characterization of $\mathbf{1 a}$ and of the three co-crystals $\mathbf{4}$, 5a, and 5b.The ${ }^{13} \mathrm{C}$ Cross Polarization Magic Angle Spinning(CPMAS)spectrum of $\mathbf{1 a}$ is characterized by a broad resonance at $14.4 \mathrm{ppm}$ assigned to $\mathrm{C}$ (Figure 7). This carbon gives a signal at $6.97 \mathrm{ppm}$ in $\mathrm{CDCl}_{3}$ solution and at $18.58 \mathrm{ppm}$ in $\mathrm{C}_{6} \mathrm{D}_{5} \mathrm{~N}$ solution, indicating that the $\mathrm{C} 1$ chemical shift moves upfield when the iodine atom is halogen-bonded. ${ }^{4}$ The observed chemical shift in 1a is in agreement with the presence of a XB between the iodine atom and the $\pi$ electrons of the triple bond. While the details of the relationship between XB strength and the upfield shift of $\mathrm{C} 1$ remains to be established,

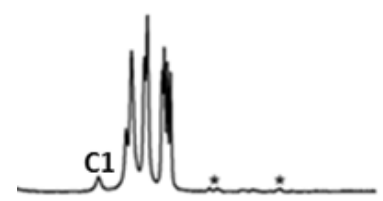

$5 b$

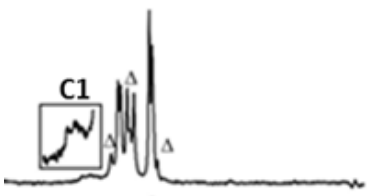

$5 a$

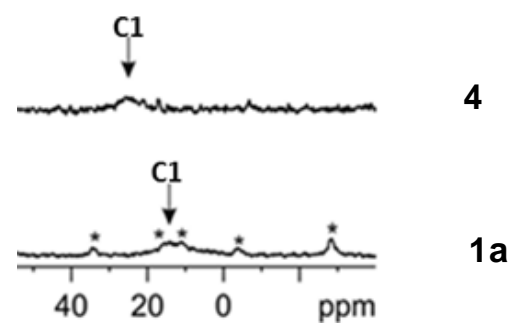

Figure $7 .{ }^{13} \mathrm{C}(100.65 \mathrm{MHz}) \mathrm{CPMAS}$ spectra (region of the $\mathrm{C} 1$ resonance) of 1aand cocrystals $\mathbf{4}$ and $\mathbf{5 a}$,brecorded at the spinning of $12 / 13 \mathrm{kHz}$. Asterisks and triangles mark spinning sidebands and unreacted 3a, respectively.

the small difference between the chemical shift of 1ain the solid and its chloroform solution (where no, or negligibly weak, XBs are present), may suggest the $\mathrm{I} \cdots \pi$ electrons in $\mathbf{1 a}$ is a mediumstrength XB.

It is expected the $\mathrm{I} \cdots \mathrm{N} \mathrm{XB}$, present in co-crystal $\mathbf{4}$, is stronger than the $\mathrm{I} \cdots \pi$ electrons $\mathrm{XB}$, occurring in $\mathbf{1 a}$, and the $\mathrm{C} 1$ signal in crystalline 4 is at $25.1 \mathrm{ppm}$ (Figure 7). The presence of

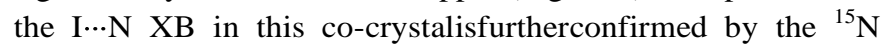
(40.55 MHz) CPMAS spectra (see ESI) showing that the pyridine nitrogen moves from 289.0 (in pure 2) to $273.7 \mathrm{ppm}$ (in co-crystal 4).

As far as the SSNMR spectra of the ionic co-crystals 5aand $\mathbf{5 b}$ are concerned, the $\mathrm{C} 1$ signal is found at 31.6 and $33.0 \mathrm{ppm}$ in 3aand 3b complexes, respectively(Figure 7). Thesechemical shifts are consistent with the formation of $\mathrm{C}-\mathrm{I} \cdots \mathrm{Y}^{-}$synthons $(\mathrm{Y}=\mathrm{I}, \mathrm{Cl})$ and they may also suggest that chloride anionsare better XBacceptors than the iodide anion and that halides are better XB acceptors than neutral pyridine species.

\section{Conclusions}

In summary, herein we have reported a polymorph and cocrystal screening study of theantifungalagent haloprogin $(1,2,4-$ trichloro-5-[(3-iodoprop-2-yn-1-yl)oxy]benzene, 1), a wellknown halogenated API. We have described three polymorphs and three co-crystals involving both neutral and ionic CCFs. These are the first crystal structures reported in the CSD involving 1. 
In the described cases, the 1-iodoalkyne moiety has been shownto be a very good XBdonor. In the crystallization of pure haloprogin, the iodine atom probes the accessible electron donor sites and the three obtained polymorphs result from this sampling process, the iodine atom binding to the $\pi$-electrons of the triple bond (in 1a), one chlorine atom (in 1b), and one chlorine and oxygen atom (in 1c). When more effective electron donor sites are made accessible by the presence of the CCFs $\mathbf{2}$ and $\mathbf{3 a}, \mathbf{b}$, co-crystals are formed wherein the iodine atom binds to the pyridine nitrogen (in 4 ) and the halide anions (in $\mathbf{5 a}, \mathbf{b})$.

The obtained crystals have been fully characterized with various techniques (single crystal and powder X-ray crystallography, solid-state NMR, IR, and DSC), which have all shown that $\mathrm{XB}$ is a key interaction responsible for the adopted architectures in the described systems. The strategy reported in this paper is general and may find wide application in the design of new pharmaceutical polymorphs and co-crystals involving halogenated active pharmaceutical ingredients.

\section{Acknowledgements}

P.M., G.R., and G.T. thank Fondazione Cariplo (grant number 2010-1351) and MIUR (projects PRIN 2010-2011, grant numbers 2010CX2TLM_004 and 2010ERFKXL_005) for financial support.

\section{Notes and references}

${ }^{a}$ NFMLab-Laboratory of Nanostructured Fluorinated Materials (NFMLab), Department of Chemistry, Materials, and Chemical Engineering "Giulio Natta", Politecnico di Milano, Via L. Mancinelli 7, 20131 Milan, Italy.

${ }^{b}$ Department of Chemistry, Università di Torino, Via P. Giuria 7, 10125 Torino, Italy.

${ }^{\dagger}$ Electronic Supplementary Information (ESI) available: Synthetic procedures, DSC plots, FTIR spectra, powder XRD plots, and details of the CSD search. See DOI:10.1039/b000000x.

1 (a) W. Jones, W. D. S. Motherwell and A. V. Trask, MRS Bulletin, 2006, 31, 875; (b) P. Vishweshwar, J. A. McMahon, J. A. Bis and M. J. Zaworotko, J. Pharm. Sci., 2006, 95, 499; (c) N. Issa, P. G. Karamertzanis, G. W. Welch and S. L. Price, Cryst. Growth Des.,2009, 9, 442; (d) C. B. Aakeröy, S. Forbes and J. Desper, J. Am. Chem. Soc., 2009, 131, 17048; (e) C. B. Aakeröy, A. B. Grommet and J. Desper, Pharmaceutics,2011, 3, 601; (f) D. R. Weyna, M. L. Cheney, N. Shan, M. Hanna, Ł. Wojtas and M. J. Zaworotko, CrystEngComm,2012, 14, 2377; (g) F. L. F. Soares and R. L. Carneiro, Cryst. Growth Des.,2013, 13, 1510.4

2 A. Lemmerer, J. Bernstein, J. Chem. Crystallogr.,2011, 41, 991.

3 A halogen bond occurs when there is evidence of a net attractive interaction between an electrophilic region associated with a halogen atom in a molecular entity and a nucleophilic region in another, or the same, molecular entity. G. R. Desiraju, P. S. Ho, L. Kloo, A. C. Legon, R. Marquardt, P. Metrangolo, P. Politzer, G. Resnati and K. Rissanen, Pure Appl. Chem. 2013, 85, 1711.
4 M. Baldrighi, G. Cavallo, M. R. Chierotti, R. Gobetto, P. Metrangolo, T. Pilati, G. Resnati, and G. Terraneo, Mol. Pharm., 2013, 10, 1760.

5 (a) E. F. Harrison, P. Zwadyk, R. J. Bequette, E. E. Hamlow, P. A. Tavormina and W. A. Zygmunt, Applied Microbiology, 1970, 19, 746; (b) E. F. Harrison and W. A. Zygmunt, Can. J. Microb., 1974, 20, 1241; (c) E. Gregori-Puigjané, V. Setola, J. Hert, B. A. Crews, J. J. Irwin, E. Lounkine, L. Marnett, B. L. Roth and B. K. Shoichet, Proc. Natl. Acad. Sci. U.S.A., 2012, 109, 11178; (d) G. Stuettgen, J. Mueller and W. Roelz, Antimycotic preparations in a cream or ointment base, 1983, GB2116425A; (e) I. R. McGraw, Use of Haloprogin to treat Herpes Labialis, 1984, US4434183; (f) J. Ponikau, Use of antifungal agents for the topical treatment of fungusinduced mucositis, 2007, EP1024814.

6 F. H. Allen, Acta Crystallogr. B, 2002, 58, 380.

7 C. B. Aakeröy, M. Baldrighi, J. Desper, P. Metrangolo and G. Resnati, Chem. Eur. J., 2013, 19, 16240.

8 T. Clark, M. Hennemann, J. S. Murray and P. Politzer, J. Mol. Model. 2007, 13, 291.

9 (a) P. Metrangolo, F. Meyer, T. Pilati, G. Resnati and G. Terraneo, Angew Chem. Int. Ed. 2008, 47, 6114; (b) M. Fourmigué, Curr. Opin. Solid State Mater. Sci., 2009, 13, 36; (c) T. M. Beale, M. G. Chudzinski, M. G. Sarwar and M. S. Taylor, Chem. Soc. Rev., 2012, 42, 1667; (d) M. Erdélyi, Chem. Soc. Rev., 2012, 41, 3547; (e) F. Meyer and P. Dubois CrystEngComm,2013, 15, 3058; (f) G. Cavallo, A. Priimagi, P. Metrangolo and G. Resnati, Acc. Chem. Res., 2013, 46, 2686; (g) R. W.Troff,T. Makela, F. Topic, A. Valkonen, K. Raatikainen, K. Rissanen, Kari, Eur. J. Org. Chem.2013, 9, 1617.

10 C. Perkins, S. Libri, H. Adams and L. Brammer, CrystEngComm, 2012, 14, 3033.

11 D. Braga, F. Grepioni, L. Maini, D. Capucci, S. Nanna, J. Wouters, L. Aerts and L. Quéré, Chem. Commun., 2012, 48, 8219.

12 GRAS (Generally Recognized As Safe) Notices: http://www.cfsan.fda.gov/ rdb/opa-gras.html.

13 J. Fellig, J. R. Barnes, A. I. Rachlin, J. P. O’Brien and A. Focella, J. Agr. Food Chem., 1970, 18, 78.

14 Saint Plus, v.6.01, Bruker Analytical X-ray, Madison, WI, 1999.

15 (a) Sheldrick, G. M. SADABS: Empirical Absorption Correction Program, University of Gottingen, Germany, 2001. Based upon the method of Blessing; (b) R. H. Blessing, Acta Crystallogr. A, 1995, 51, 33 .

16 APEXII v2009. 5-1, (C) 2009, Bruker Analytical X-ray Systems, Madison, WI

17 G. M. Sheldrick, Acta Crystallogr. A, 2008, 64, 112.

18 L. J. Farrugia, J. Appl. Crystallogr., 1999, 32, 837.

19 Mercury 3.1, (C) CCDC 2001-2012.

20 Spartan'10, Wavefunction Inc., Irvine, CA.

21 C. J. Adams and L. E. Bowen, Dalton Trans., 2005, 2239; T. Graening, V. Bette, J. Neudorfl, J. Lex and H.-G. Schmalz, Org. Lett., 2005, 7, 4317; A.-L. Barres, A. El-Ghayoury, L. V. Zorina, E. Canadell, P. Auban-Senzier and P. Batail, Chem. Commun., 2008, 44, 2194.

22 A. Bondi, J. Phys. Chem., 1964, 68, 441.

23 (a) A.B. Sheremetev, J.L .Shamshina, D.E. Dmitriev, D.V. Lyubetskii and M.Y. Antipin, Heteroat. Chem., 2004, 15, 199; (b) L. Ouahab, F. 
Setifi, S. Golhen, T. Imakubo, R. Lescouezec, F. Lloret, M. Julve and R. Swietlik, Comptes Rendus Chimie, 2005, 8, 1286; (c) K.D. Scherfise, F. Weller and K. Dehnicke, Z. Naturforsch.,B: Chem.Sci., 1985, 40, 906.

24 (a) M. R. Chierotti, and R. Gobetto, Chem. Commun., 2008, 14, 1621; (b) S. P. Brown, Solid State Nucl. Magn. Reson., 2012, 41, 1; (c) X. Filip, I. G. Grosu, M. Miclaus, and C. Filip, CrystEngComm, 2013, 15, 4131.

25 (a) J. P. Bradley, C. J. Pickard, J. C. Burley, D. R. Martin, L. P. Hughes, S. D. Cosgrove and S. P. Brown, J. Pharm. Sci., 2012, 101, 1821; (b) M. U. Schmidt, J. Bruning, J. Glinnemann, M. W. Hutzler, P. Morschel, S. N. Ivashevskaya, J. van de Streek, D. Braga, L. Maini, M. R. Chierotti and R. Gobetto, Angew. Chem. Int. Ed., 2011, 50, 7924.

26 (a) C. M. Widdifield, G. Cavallo, G. A. Facey, T. Pilati, J. Lin, P. Metrangolo, G. Resnati and D. L. Bryce, Chem. Eur. J. 2013, 19, 11949; (b) J. Viger-Gravel, S. Leclerc, I. Korobkov and D. L. Bryce, CrystEngComm., 2013, 15, 3168.

27 (a) R. J. Attrell, C. M. Widdifield, I. Korobkov, and D.L. Bryce, Cryst. Growth Des., 2012, 12, 1641; (b) J. Viger-Gravel, I. Korobkov and D. L. Bryce, Cryst. Growth Des., 2011, 11, 4984; c) M. G. Chudzinski, C. A. McClary and M. S. Taylor, J. Am. Chem. Soc., 2011, 133, 10559.

28 (a) Nonappa; Lahtinen, M.; Kolehmainen, E.; Haarala, J.; Shevchenko, A.; Cryst. Growth Des., 2013, 13 346; (b) C. Lemouchi, C. S. Vogelsberg, L. Zorina, S. Simonov, P. Batail, S. Brown and M. A. Garcia-Garibay, J. Am. Chem. Soc., 2011, 133, 6371.

29 C. Pettinari, C. Di Nicola, F. Marchetti, R. Pettinari, B. W. Skelton, N. Somers, A. H. White, W. T. Robinson, M. R. Chierotti, R. Gobetto, and C. Nervi, Eur. J. Inorg. Chem. 2008, 1974. 
Electronic Supporting Information (ESI)

\section{Polymorphs and cocrystals of Haloprogin: An antifungal agent}

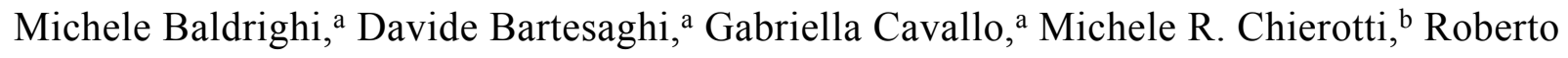
Gobetto, ${ }^{b}$ Pierangelo Metrangolo, ${ }^{* a}$ Tullio Pilati, ${ }^{a}$ Giuseppe Resnati, ${ }^{* a}$ and Giancarlo Terraneo*a

${ }^{a}$ NFMLab-Laboratory of Nanostructured Fluorinated Materials (NFMLab), Department of Chemistry, Materials, and Chemical Engineering "Giulio Natta", Politecnico di Milano, Via L. Mancinelli 7, 20131 Milan, Italy.

${ }^{b}$ Department of Chemistry, Università di Torino, Via P. Giuria 7, 10125 Torino, Italy. 
Index:

1. Synthesis of $(1,2,4$-trichloro-5-[(3-iodoprop-2-yn-1-yl)oxy]benzene, 1$)$

1.1. Synthesis of 1,2,4-trichloro-5-(prop-2-yn-1-yloxy)benzene (A).

1.2. Synthesis of 1,2,4-trichloro-5-((3-iodoprop-2-yn-1-yl)oxy)benzene (1).

1.3. Crystallization experiments.

2. Thermal analysis (DSC plots)

2.1. DSC plot of polymorphs $1 \mathrm{a}$ and $1 \mathrm{~b}$.

2.2. DSC plots of co-crystals $4,5 a$, and $5 b$.

3. Vibrational spectra (FTIR)

3.1. FTIR spectrum of $1 \mathrm{a}$.

3.2. FTIR spectrum of $1 \mathrm{~b}$.

3.3. FTIR spectrum of 4 .

3.4. FTIR spectrum of 5 a.

3.5. FTIR spectrum of $5 \mathrm{~b}$.

4. Powder XRD

4.1. PXRD pattern of 1 a.

4.2. PXRD pattern of mixture of polymorphs $1 \mathrm{a}$ and $1 \mathrm{~b}$.

4.3. PXRD pattern of 4 .

4.4. PXRD pattern of 5a.

4.5. PXRD pattern of $5 \mathrm{~b}$.

5. SSNMR

5.1. Chemical shift assignments.

5.2. Full ${ }^{13} \mathrm{C}$ CPMAS spectra of $5 \mathrm{~b}, 3 \mathrm{~b}, 5 \mathrm{a}, 3 \mathrm{a}, 4,2$, and 1 a from top to bottom, respectively.

5.3. ${ }^{15} \mathrm{~N}$ CPMAS spectra.

6. Cambridge Structural Database (CSD) Search

6.1. XB contacts involving iodoethynyl moiety and $\pi$-electrons of triple bond. 


\section{Synthesis of (1,2,4-trichloro-5-[(3-iodoprop-2-yn-1-yl)oxy]benzene, 1)}

1.1. Synthesis of 1,2,4-trichloro-5-(prop-2-yn-1-yloxy)benzene (A): in a round bottom flask equipped with a magnetic stirrer were mixed $1.0 \mathrm{~g}$ of 2,4,5-trichlorophenol (5.06 mmol), 662.6 $\mathrm{mg}$ of 3-bromo-1-propyne $(5.57 \mathrm{mmol})$ and $768.6 \mathrm{mg}(5.57 \mathrm{mmol})$ of potassium carbonate dissolved in $8 \mathrm{~mL}$ of acetone. The reaction was stirred under reflux for 5 hours, and allowed to cool down, then the solids were filtered and the solution was evaporated under vacuum, giving $1.165 \mathrm{~g}(98 \%)$ of pure product. M.p. $63-64{ }^{\circ} \mathrm{C}$; FTIR (selected bands):3092, 2984, 2122, 1476, 1457, 1235, 1080, 1024, 870, $672 \mathrm{~cm}^{-1} ;{ }^{1} \mathrm{H} \mathrm{NMR}\left(400 \mathrm{MHz}, \mathrm{CDCl}_{3}\right) \delta(\mathrm{ppm}) 7.47(\mathrm{~s}, 1 \mathrm{H}), 7.18$ $(\mathrm{s}, 1 \mathrm{H}), 4.76(\mathrm{~d}, J=2.4 \mathrm{~Hz}, 2 \mathrm{H}), 2.59(\mathrm{t}, J=2.4 \mathrm{~Hz}, 1 \mathrm{H}) .{ }^{13} \mathrm{C} \mathrm{NMR}\left(101 \mathrm{MHz}, \mathrm{CDCl}_{3}\right) \delta(\mathrm{ppm})$ $152.32,131.31,131.28,125.55,122.83,116.23,77.24,77.12,57.52$.

1.2. Synthesis of 1,2,4-trichloro-5-((3-iodoprop-2-yn-1-yl)oxy)benzene (Haloprogin, 1): a round bottom flask equipped with a magnetic stirrer was charged with $200 \mathrm{mg}$ of $\mathbf{A}(0.85 \mathrm{mmol})$ dissolved in $15 \mathrm{~mL}$ of methanol. A solution of iodine $(284 \mathrm{mg}, 1.12 \mathrm{mmol})$ in methanol and a $10 \%$ water solution of sodium hydroxide $(77.5 \mathrm{mg}, 1.94 \mathrm{mmol})$ were dropped simultaneously over 20 minutes. The reaction was stirred overnight, then $20 \mathrm{~mL}$ of water were added, causing the formation of a white precipitate. The mixture was stirred for $30 \mathrm{~min}$, then the solid material was recovered by filtration, washed two times with cold water and dried over a nitrogen flux, affording $221 \mathrm{mg}$ of the pure product (72\% yield). M.p.: 111-112 ${ }^{\circ} \mathrm{C}$; FTIR (selected bands): $2187,1581,1472,1453,1232,1077,1028,866,724,681 \mathrm{~cm}^{-1} .{ }^{1} \mathrm{H}$ NMR $\left(400 \mathrm{MHz}, \mathrm{CDCl}_{3}\right) \delta$ (ppm) $7.46(\mathrm{~s}, 1 \mathrm{H}), 7.15(\mathrm{~s}, 1 \mathrm{H}), 4.89(\mathrm{~s}, 2 \mathrm{H}) .{ }^{13} \mathrm{C} \mathrm{NMR}\left(101 \mathrm{MHz}, \mathrm{CDCl}_{3}\right) \delta 152.20(\mathrm{C} 4)$, 131.22(C8), 131.13(C6), 125.51(C7), 122.73 (C5), 116.16 (C9), 87.64 (C2), 58.91 (C3), 6.97 (C1). ${ }^{13} \mathrm{C}$ NMR (101 MHz, $\left.\mathrm{C}_{5} \mathrm{D}_{5} \mathrm{~N}\right) \delta(\mathrm{ppm}) 152.65$ (C4), 131.14 (C8), 131.10 (C6), 124.62 (C7), 122.40(C5), 116.14 (C9), 86.78(C2), 59.06 (C3), 18.58 (C1). 


\subsection{Crystallization experiments.}

General crystallization procedure: in a $2.5 \mathrm{~mL}$ glass vial $10 \mathrm{mg}$ of $1(0.027 \mathrm{mmol})$ were dissolved in $1.5 \mathrm{~mL}$ of the selected organic solvent or solvent mixture (see below). The vial was left open under a hood at room temperature in order to allow the evaporation of the solvent. The identification of the obtained form was performed by checking the unit cell parameters of selected crystals.

\begin{tabular}{|c|c|}
\hline Crystallization solvent & Obtained form \\
\hline $\mathrm{CHCl}_{3}$ & $1 \mathrm{a}$ \\
\hline $\mathrm{MeOH}$ & $1 \mathbf{a}$ \\
\hline $\mathrm{CH}_{2} \mathrm{Cl}_{2}$ & $1 \mathbf{a}$ \\
\hline $\mathrm{CH}_{3} \mathrm{CN}$ & $1 \mathbf{a}$ \\
\hline DMSO & $1 \mathbf{a}$ \\
\hline $\mathrm{CHCl}_{3} / \mathrm{MeOH} 9: 1 ; 1: 1 ; 1: 9$ & $1 \mathbf{a}$ \\
\hline $\mathrm{CHCl}_{3} / \mathrm{MeOH} / \mathrm{CH}_{3} \mathrm{CO}_{2} \mathrm{Na}$ & $1 b$ and $1 c$ \\
\hline
\end{tabular}




\section{Thermal analysis (DSC plots)}

2.1. DSC of polymorph 1a (left) and $1 \mathrm{~b}$ (right).

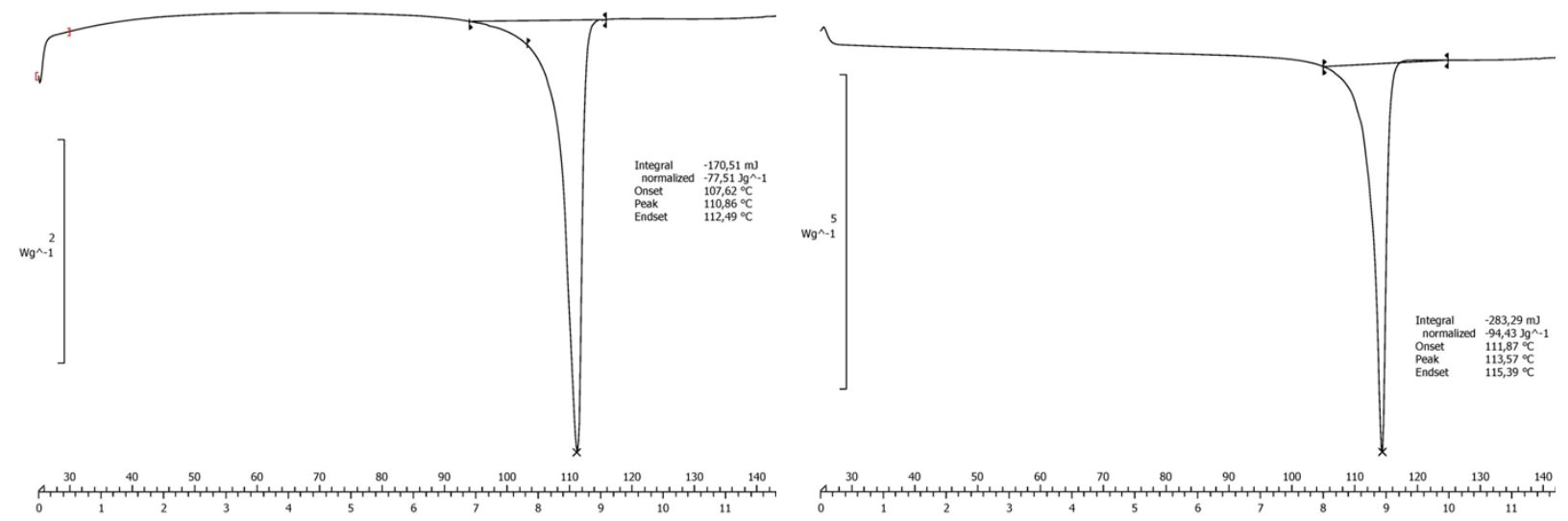

2.2. DSC of 4 (left), 5a (mid), and $5 b$ (right).
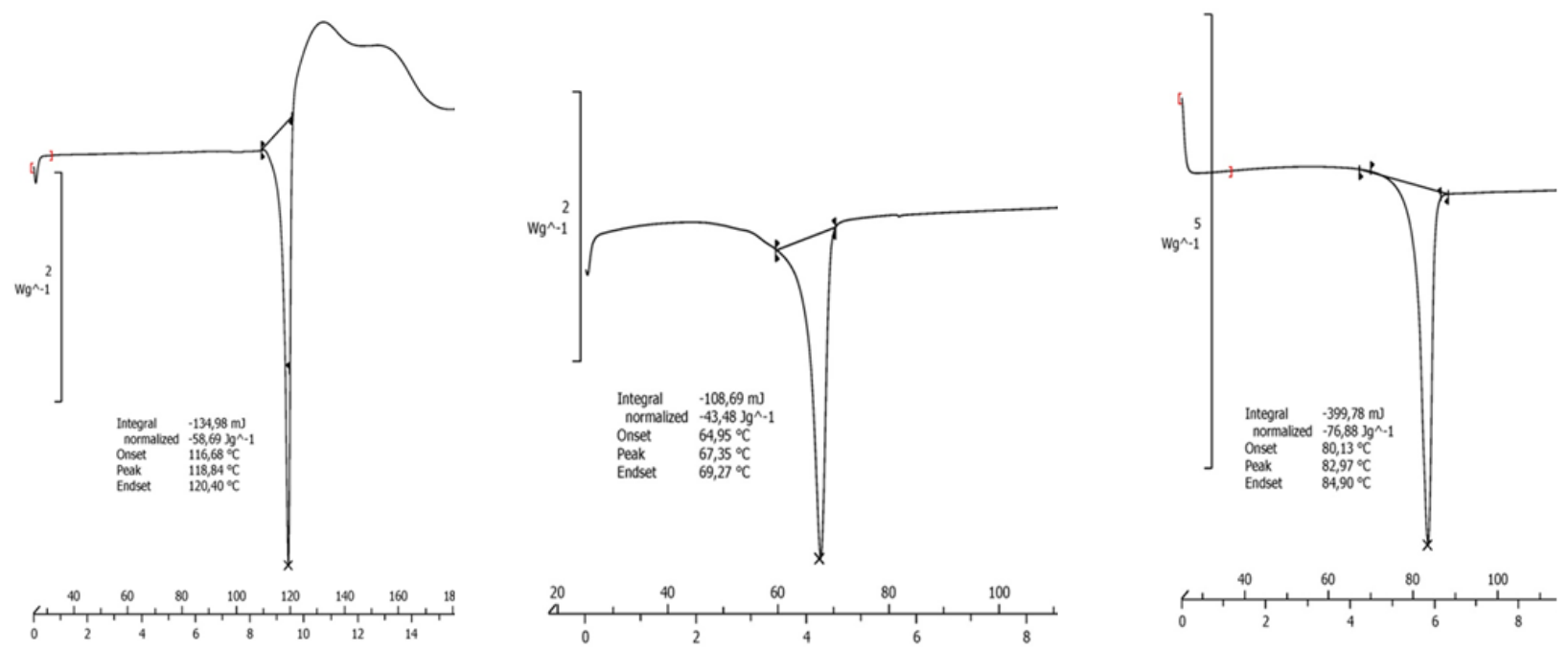


\section{Vibration spectra (FTIR)}

\subsection{FTIR spectrum of 1a.}

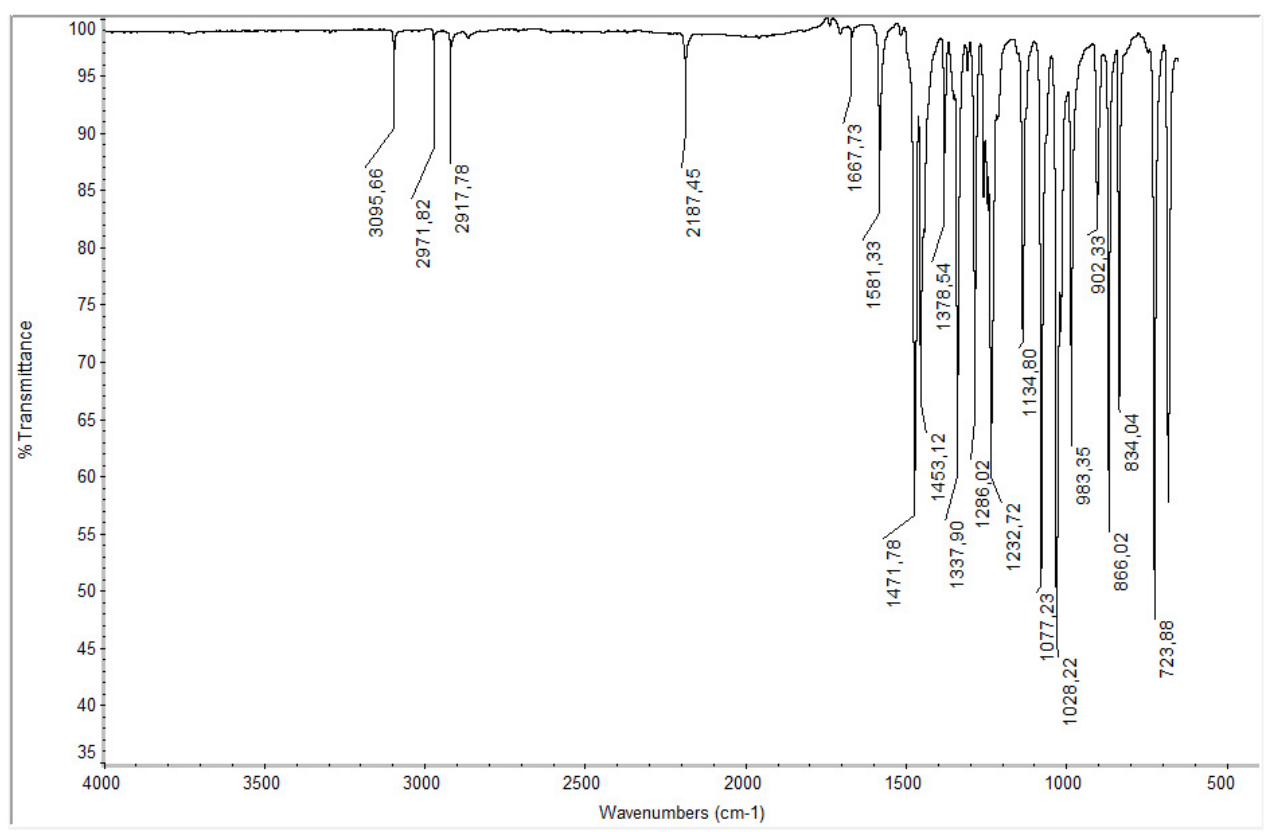

\subsection{FTIR spectrum of $\mathbf{1 b}$.}

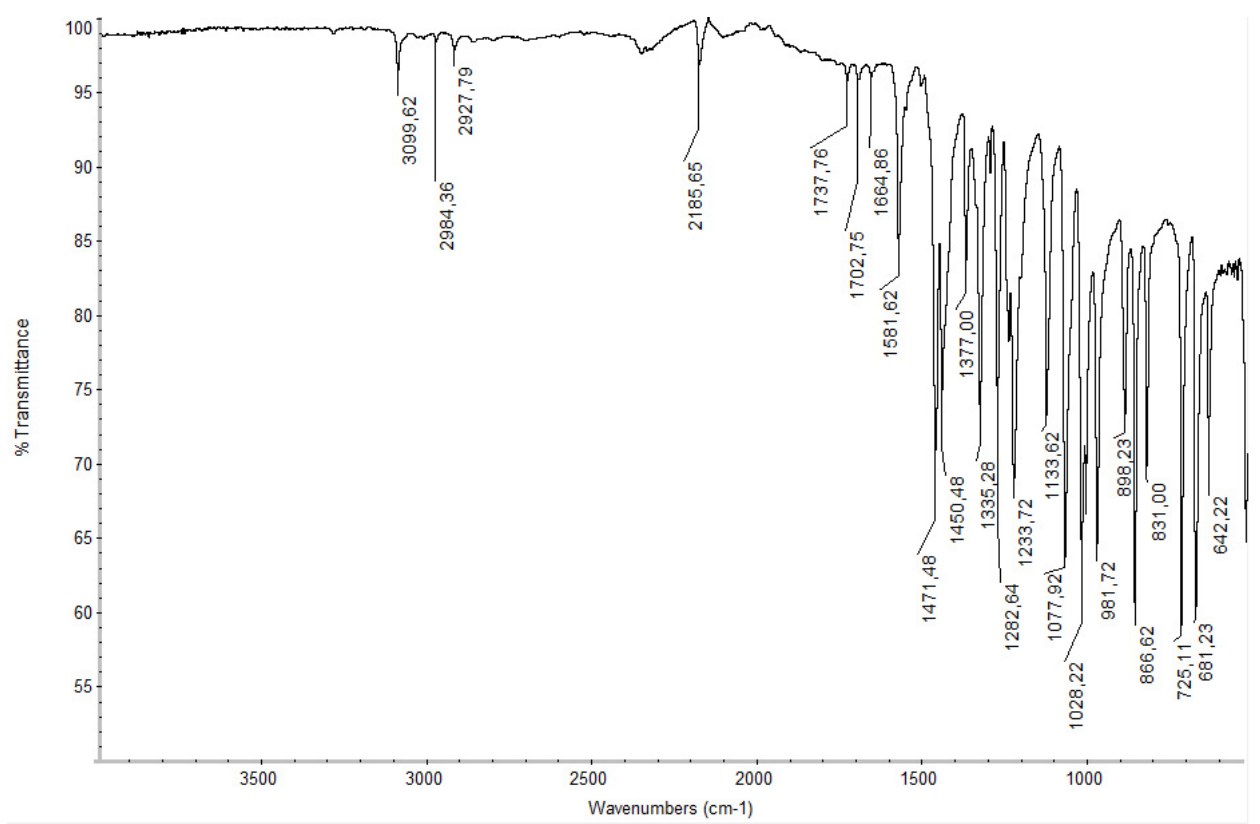


3.3. FTIR spectrum of 4 .

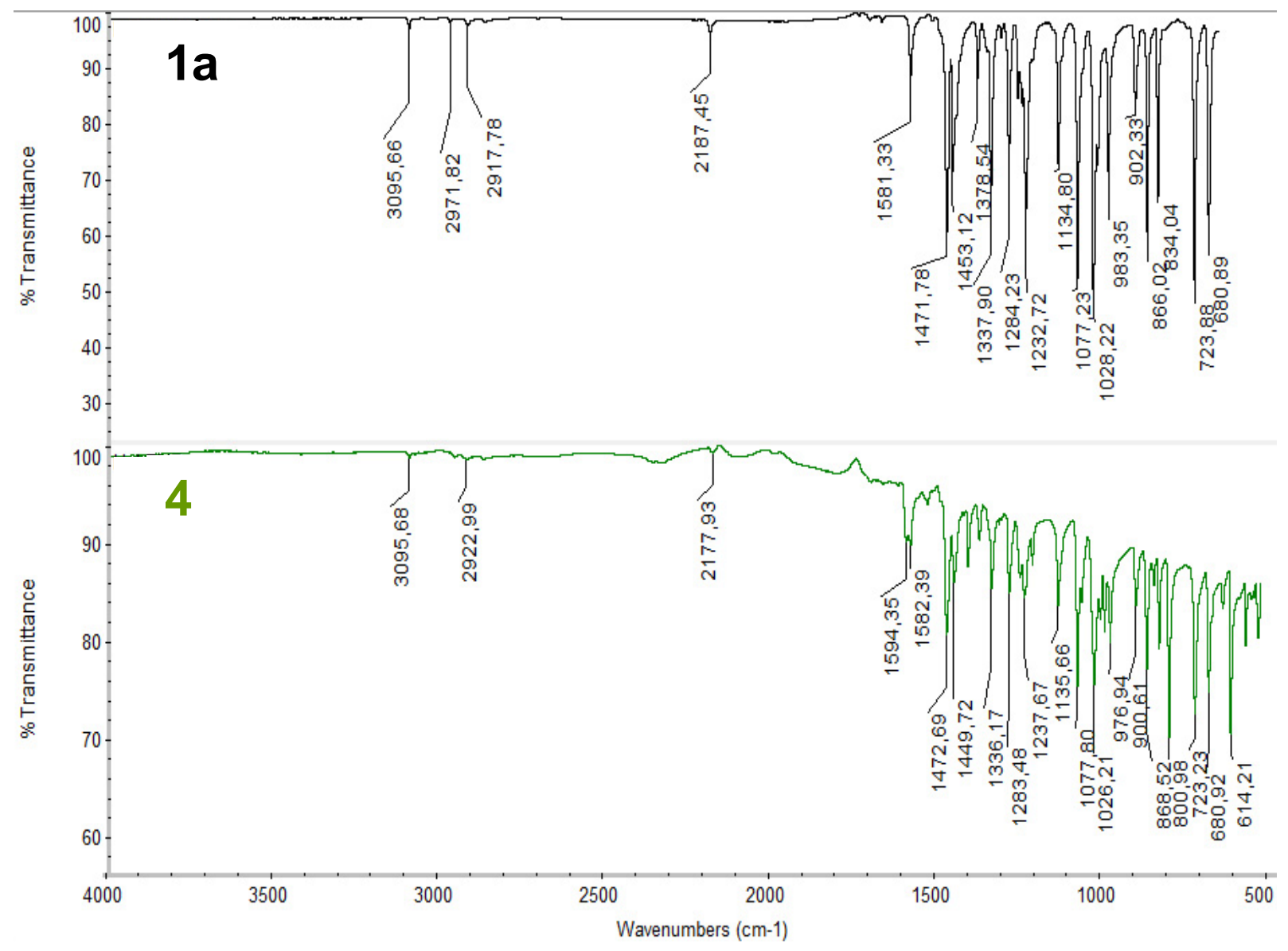




\subsection{FTIR spectrum of 5a.}

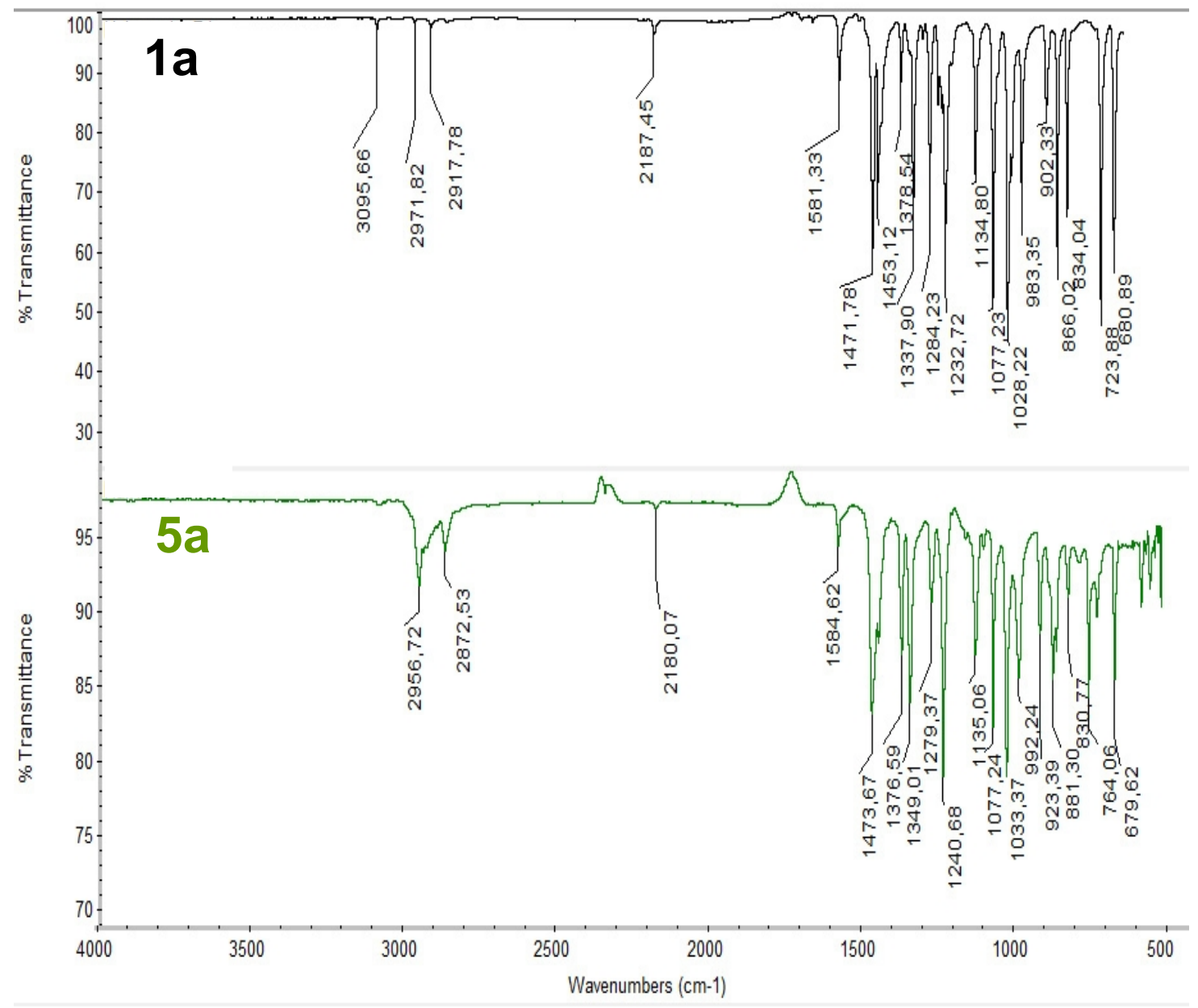




\subsection{FTIR spectrum of $5 \mathrm{~b}$.}

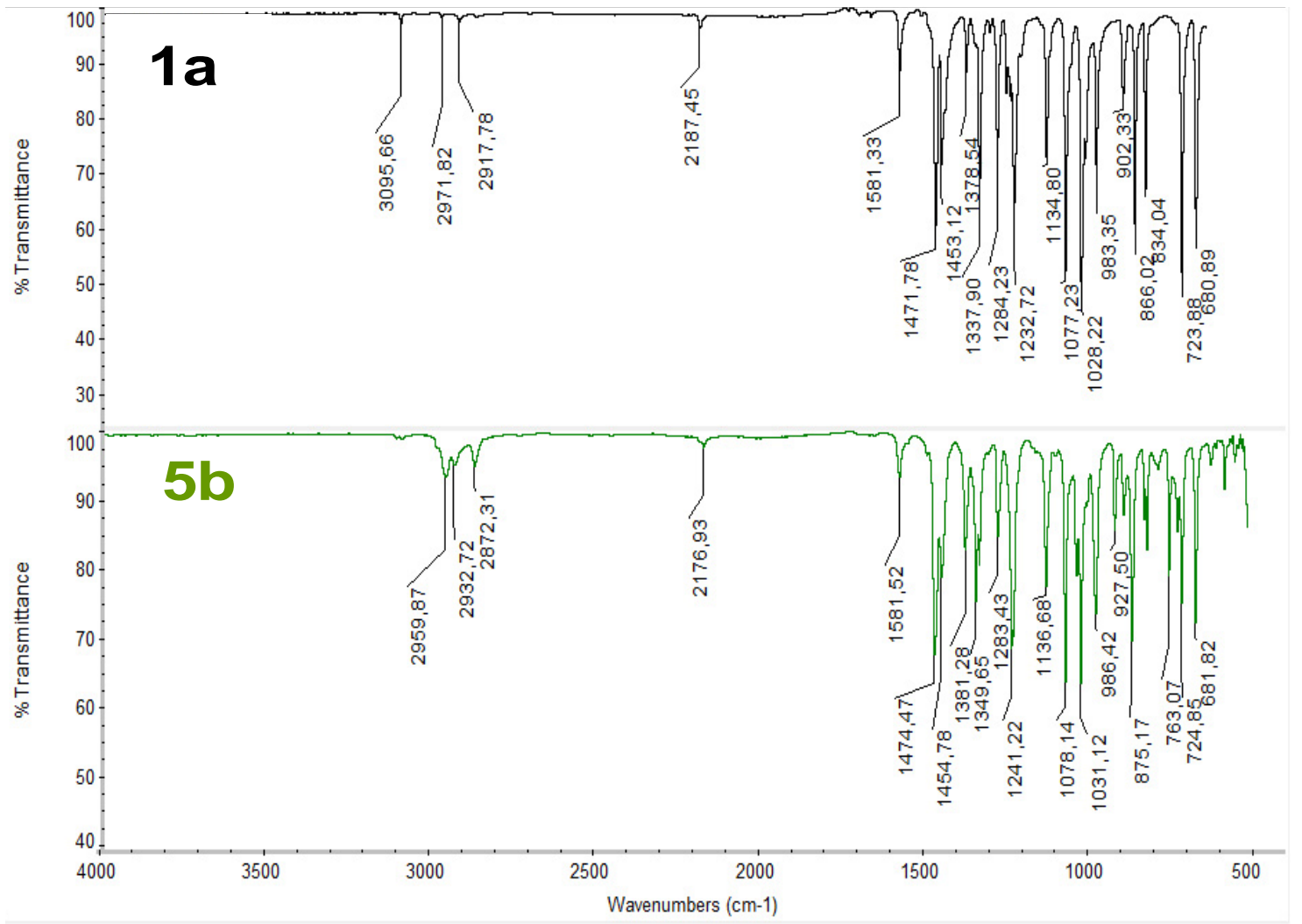




\section{Powder XRD}

\subsection{PXRD pattern of polymorph 1a.}

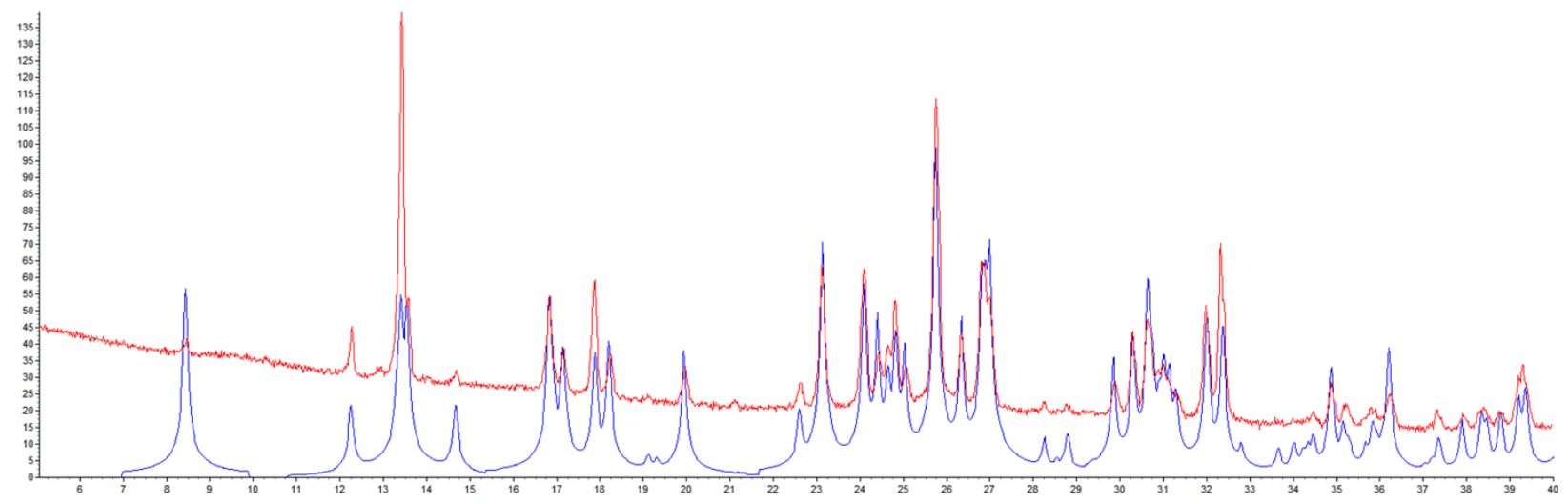

Red line: experimental powder pattern of 1a. Blue line: simulated from single crystal of $\mathbf{1 a .}$ 


\subsection{PXRD pattern of mixture of polymorphs $1 \mathrm{a}$ and $1 \mathrm{~b}$.}

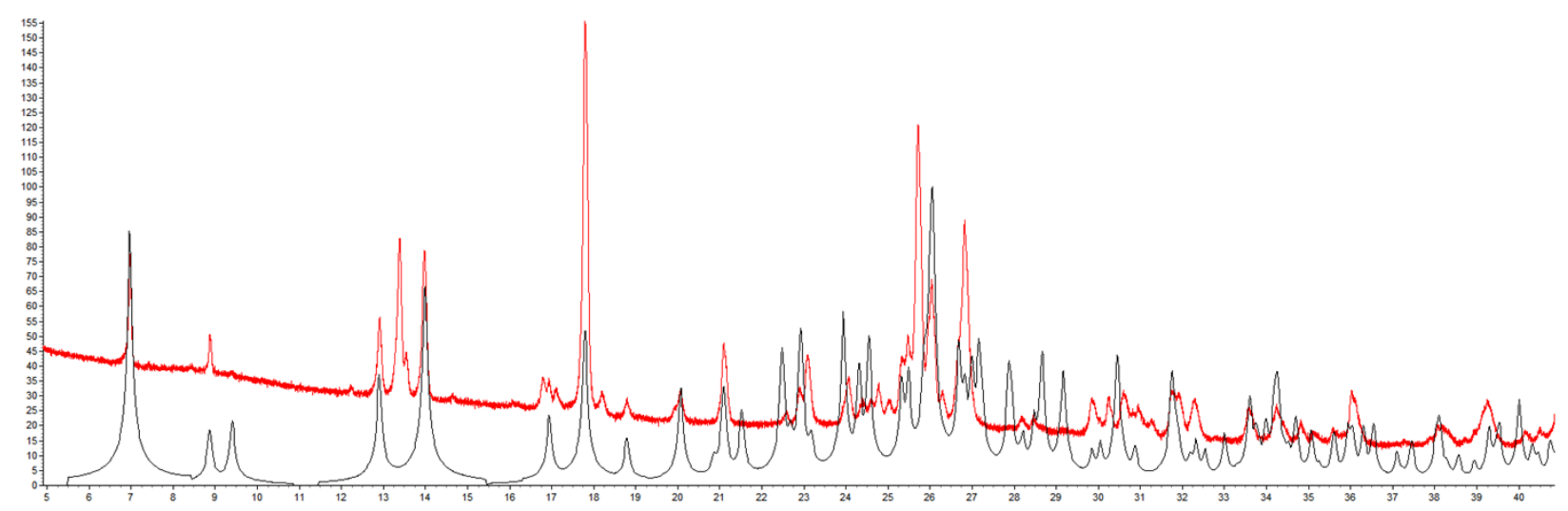

Red line: experimental powder pattern of $\mathbf{1 b}$ and 1a mixture. Black line: simulated from single crystal of $\mathbf{1 b}$.

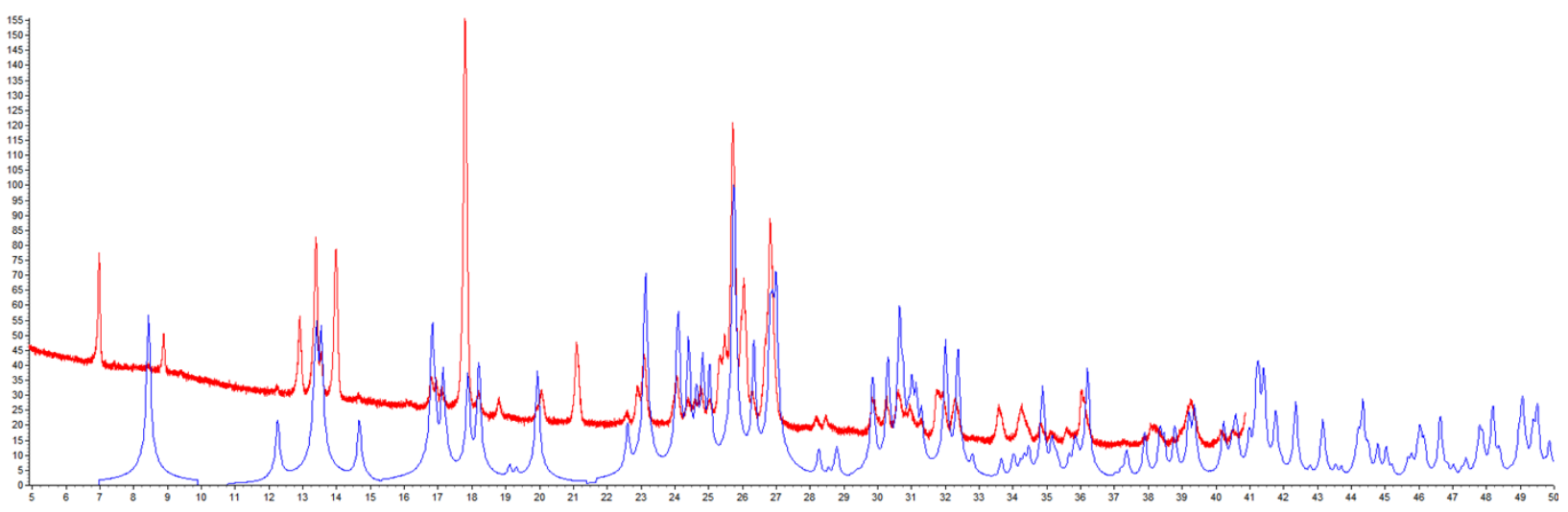

Red line: experimental powder pattern of $\mathbf{1 b}$ and 1a mixture. Blue line: simulated from single crystal of 1 a.

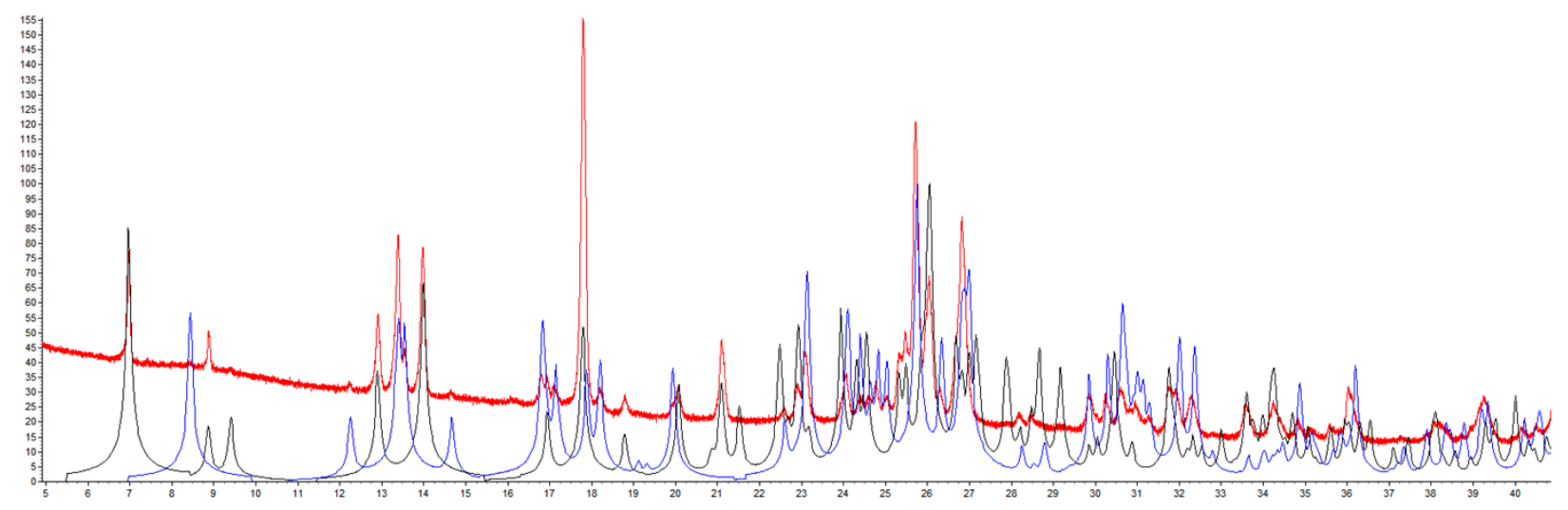

Red line: experimental powder pattern of $\mathbf{1 b}$ and 1a mixture. Blue line: simulated from single crystal of 1a. Black line: simulated from single crystal of $\mathbf{1 b .}$ 


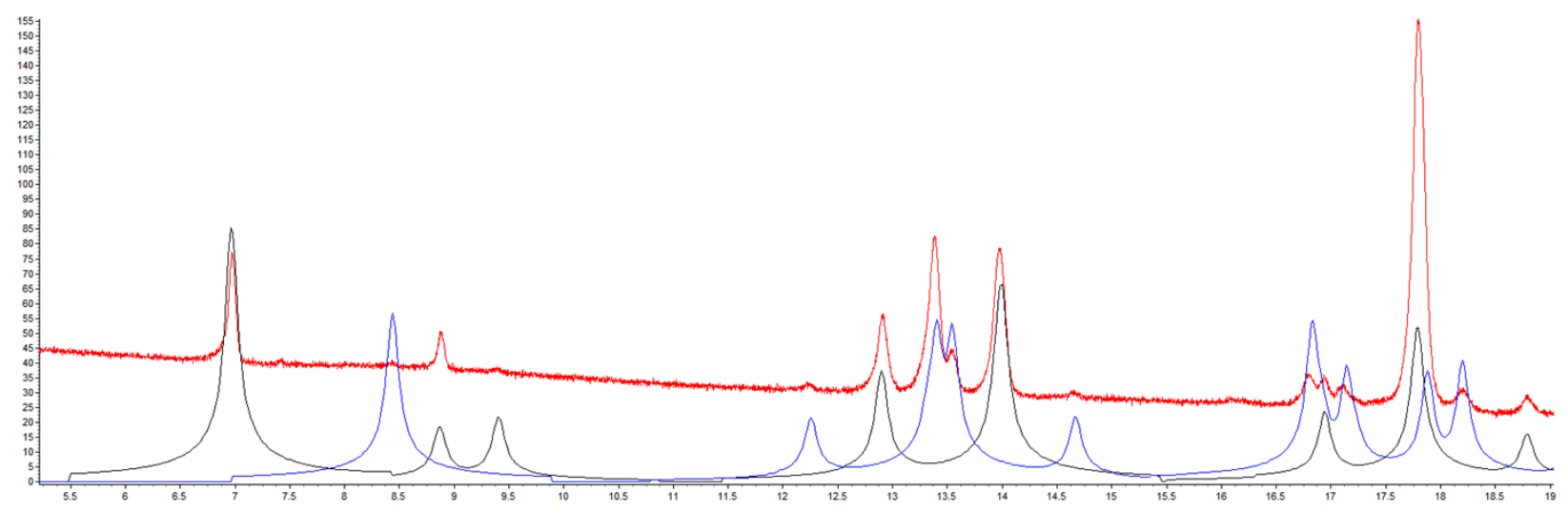

Region between $5.5^{\circ}$ and $19^{\circ}$ ( 2 theta). Red line: experimental powder pattern of $\mathbf{1 b}$ and $\mathbf{1 a}$ mixture. Blue line: simulated from single crystal of 1a. Black line: simulated from single crystal of $\mathbf{1 b}$.

The polymorph 1b was obtained when a chloroform solution of haloprogin was allowed to slowly diffuse into a saturated methanol solution of sodium acetate and the resulting solvents mixture was slowly evaporated at room temperature. Few crystals of $\mathbf{1 b}$ were obtained along with massive quantities of 1a. The samples used in PXRD experiment were obtained by selecting the $1 \mathbf{b}$ crystals over 1a. Therefore since $\mathbf{1 b}$ crystals were always obtained along with large quantities of $\mathbf{1 a}$ the reported powder patterns show a mixture of $\mathbf{1 b}$ and $\mathbf{1 a}$.

The number of crystals for the polymorph 1c were very few (much lower than $\mathbf{1 b}$ ) and extremely unstable. The low stability and the insufficient amount of this sample did not allow for the obtainment of PXRD data. 


\subsection{PXRD pattern of co-crystal 4.}

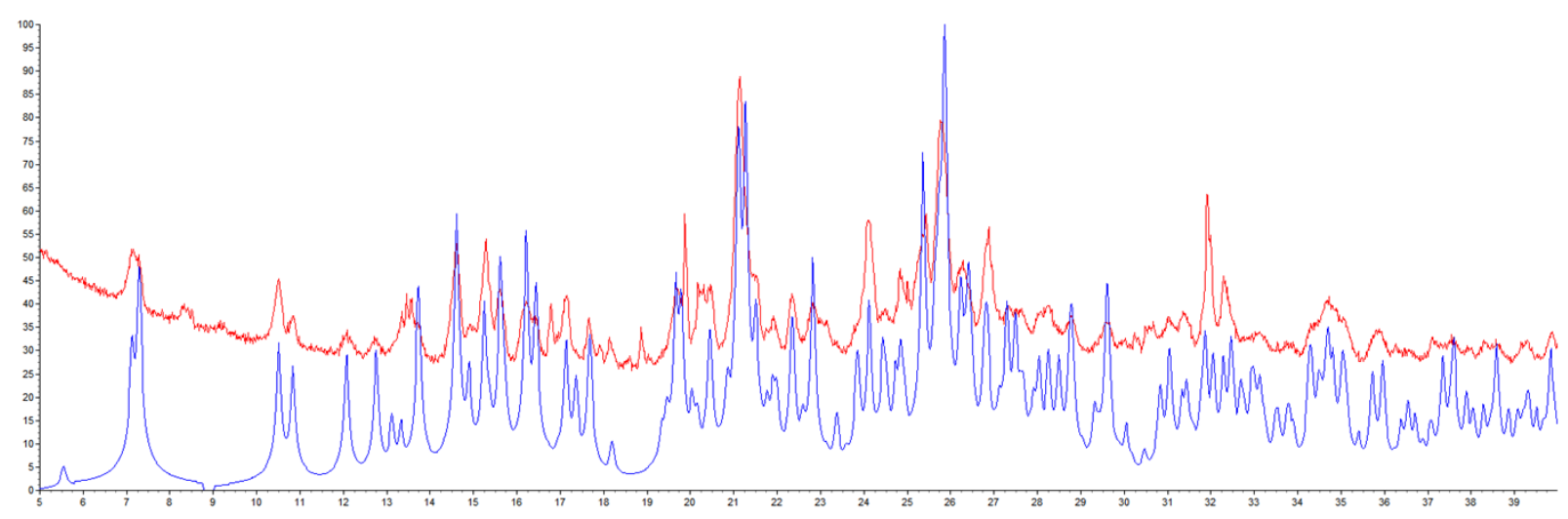

Red line: experimental powder pattern of 4. Blue line: simulated from single crystal of 4 .

The sample of $\mathbf{4}$ was prepared by slow evaporation and then was finely ground. 


\subsection{PXRD pattern of co-crystal 5a.}

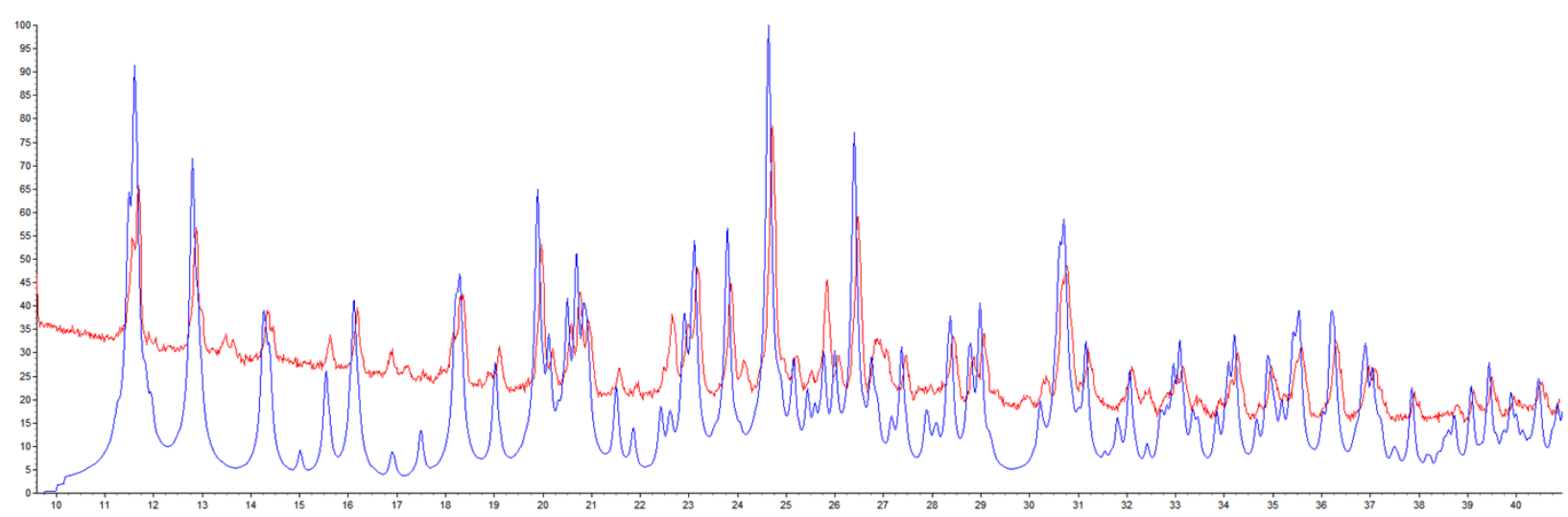

Red line: experimental powder pattern of 5a. Blue line: simulated from single crystal of $\mathbf{5 a}$. 


\subsection{PXRD pattern of co-crystal $5 b$.}

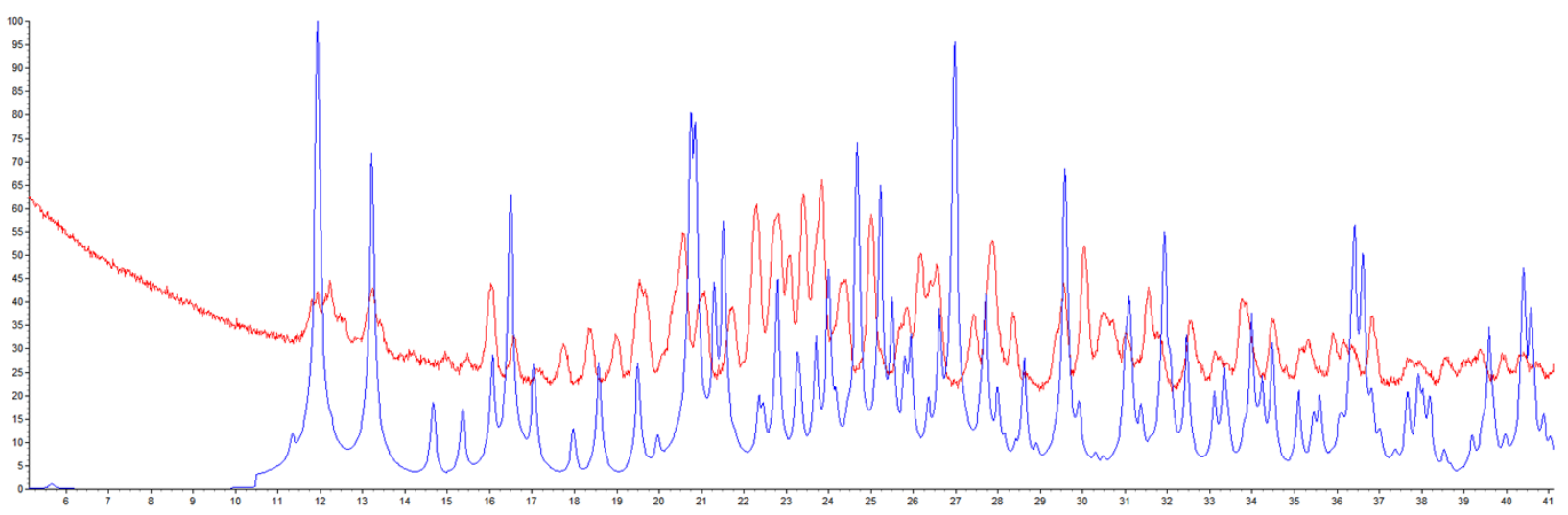

Red line: experimental powder pattern of $\mathbf{5 b}$. Blue line: simulated from single crystal of $\mathbf{5 b}$. 


\section{SSNMR}

\subsection{Chemical shift assignments}

Table S1. ${ }^{13} \mathrm{C}$ and ${ }^{15} \mathrm{~N}$ chemical shift assignments for pure reagents $(\mathbf{1 a}, \mathbf{2}, \mathbf{3 a}$, and $\mathbf{3 b})$, and for the $\mathbf{4}, \mathbf{5 a}$, and $\mathbf{5 b}$ co-crystals.

\begin{tabular}{|c|c|c|c|c|c|c|c|c|}
\hline Atom & note & 2 & 3 & 3B & $1 \mathrm{~A}$ & 4 & $5 \mathbf{A}$ & 5B \\
\hline $\mathrm{C} 1^{\mathrm{A}}$ & $\mathrm{CH}^{\mathrm{a} /} \mathrm{CH}_{2}{ }^{\mathrm{b}}$ & 149.6/148.2/146.9 & 61.3 & $56.9 / 57.3 / 57.9$ & & $151.2 / 149.8$ & $58.0 / 58.3$ & $57.3 / 62.4$ \\
\hline $\mathrm{C} 2^{\mathrm{A}}$ & $\mathrm{CH}^{\mathrm{a} /} \mathrm{CH}_{2}{ }^{\mathrm{b}}$ & $123.1 / 121.5$ & 26.3 & 23.9/24.3/24.7/25.7 & & 122.4 & $23.7 / 24.5$ & $24.4 / 25.7$ \\
\hline $\mathrm{C} 3^{\mathrm{A}}$ & $\mathrm{C}_{\mathrm{q}}{ }^{\mathrm{a}} / \mathrm{CH}_{2}{ }^{\mathrm{b}}$ & 146.9 & 21.3 & $19.9 / 21.0$ & & 146.4 & $20.3 / 22.0$ & $20.2 / 21.0$ \\
\hline $\mathrm{C} 4^{\mathrm{A}}$ & $\mathrm{CH}_{3}$ & - & $14.1 / 15.0 / 15.2$ & $14.5 / 14.8 / 15.0 / 15.3$ & & & $15.5 / 16.2$ & 14.1/14.9/15.8/16.3 \\
\hline $\mathrm{C} 1$ & $\mathrm{C}_{\mathrm{q}}$ & & & & 14.4 & 25.1 & 31.6 & 33.0 \\
\hline $\mathrm{C} 2$ & $\mathrm{C}_{\mathrm{q}}$ & & & & 91.1 & 84.6 & 81.5 & $83.1 / 86.2$ \\
\hline $\mathrm{C} 3$ & $\mathrm{CH}_{2}$ & & & & 61.3 & 58.9 & 59.0 & $60.3 / 60.9$ \\
\hline $\mathrm{C} 4$ & $\mathrm{C}_{\mathrm{q}}$ & & & & 153.7 & 152.5 & 153.1 & $152.2 / 152.9$ \\
\hline $\mathrm{C} 5$ & $\mathrm{C}_{\mathrm{q}}$ & & & & $119.5^{\mathrm{c} / 122.3^{\mathrm{c}}}$ & 120.8 & $120.5^{\mathrm{c} / 123.3^{\mathrm{c}}}$ & $121.0^{\mathrm{c}} / 121.7^{\mathrm{c}}$ \\
\hline $\mathrm{C} 6$ & $\mathrm{CH}$ & & & & 129.9 & 129.8 & 131.9 & $130.5 / 131.2$ \\
\hline $\mathrm{C} 7$ & $\mathrm{C}_{\mathrm{q}}$ & & & & $124.3 / 127.6^{\mathrm{c} / \mathrm{sh}}$ & 126.5 & $123.7^{\mathrm{c}} / 128.1^{\mathrm{c}}$ & $124.0 / 124.6$ \\
\hline $\mathrm{C} 8$ & $\mathrm{C}_{\mathrm{q}}$ & & & & 135.4 & 134.8 & 134.3 & 133.0 \\
\hline C9 & $\mathrm{CH}$ & & & & 115.5 & 114.6 & 114.4 & $114.3 / 115.0$ \\
\hline $\mathrm{N}$ & $\mathrm{N}_{\mathrm{t}}$ & 289.0 & - & - & - & 273.7 & - & - \\
\hline
\end{tabular}

a Bipyridine. ${ }^{\mathrm{b}}$ Tetra $n$-butylammonium iodide or chloride. ${ }^{\mathrm{c}}$ Two values observed due to a second-order effect of dipolar coupling to the quadrupolar chlorine-35/37 (both spin 3/2) or iodine-127 (spin 5/2) nuclei which splits or broadens the signals. 


\subsection{Full ${ }^{13} \mathrm{C}$ CPMAS spectra of $5 \mathrm{~b}, 3 \mathrm{~b}, 5 \mathrm{a}, 3 \mathrm{a}, 4,2$, and $1 \mathrm{a}$ from top to bottom,}

respectively.

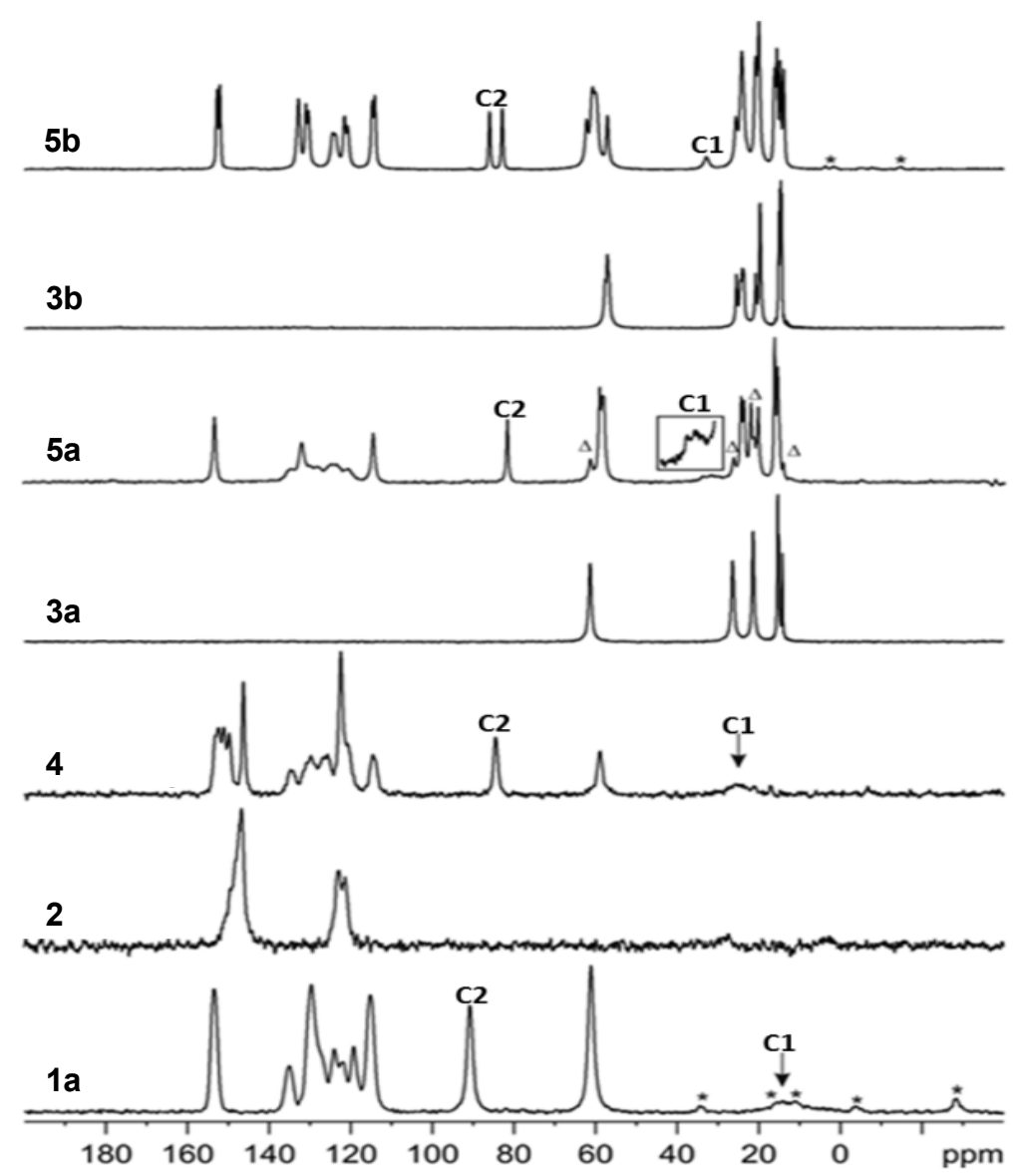

${ }^{13} \mathrm{C}(100.65 \mathrm{MHz}) \mathrm{CPMAS}$ spectra of all reagents and co-crystals were recorded at the spinning of 12/13 kHz. Asterisks and triangles mark spinning sidebands and unreacted 3a, respectively. Assignments of relevant peaks are also reported. 


\section{3. ${ }^{15} \mathrm{~N}$ CPMAS spectra.}

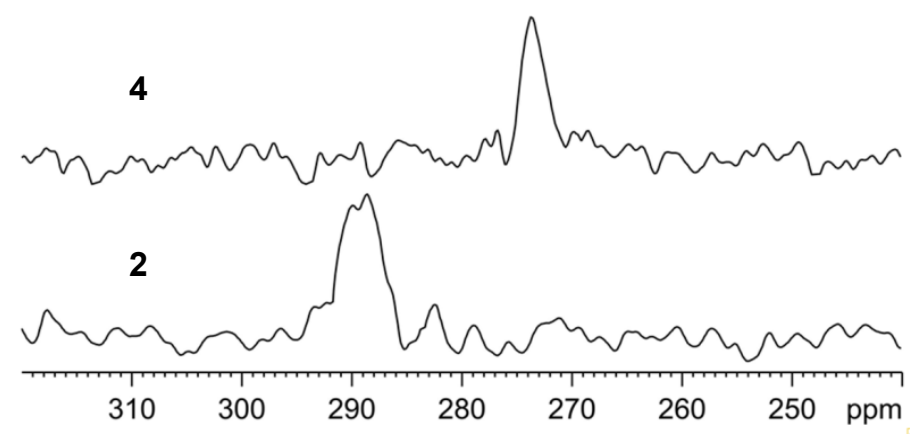

${ }^{15} \mathrm{~N}(40.55 \mathrm{MHz}$ ) CPMAS spectra of pure 2 (bottom) and of 4 (top) recorded at the spinning of 9 $\mathrm{kHz}$. 


\section{Cambridge Structural Database (CSD) Search, version 5.34, update 1 (Nov. 2012)}

\subsection{XB contacts involving the iodoethynyl moiety and $\pi$-electrons on triple bond.}

The CSD search has been performed on the fragment reported below. Restrictions: 3D coordinates, no disordered structure, no errors, no polymeric structure. Angle between CI $\cdots$ centroid of triple bond $\left(\mathrm{C}^{*}\right)$ between $140^{\circ}$ and $180^{\circ}$, distance between I and centroid of triple bond between $2 \AA$ and $3.8 \AA$.

Fragment used in the CSD search.<smiles>C#C[I-]C</smiles>

$\mathrm{N}^{\circ}$ of hits: 13

Distance I $\cdots C^{*}$ median value: $3.466 \AA$.

Angle C-I $\cdots C^{*}$ median value: $165.6^{\circ}$

\begin{tabular}{|l|}
\hline CSD Refcode \\
\hline AVIYEK \\
\hline BAMPIQ \\
\hline BOBGUV \\
\hline DIACET \\
\hline ELIMES \\
\hline QAQTOS \\
\hline RAXKOR \\
\hline RETRIR \\
\hline SIVYEC \\
\hline TOJBUQ \\
\hline XASWOD \\
\hline XUNRII \\
\hline YAPCUP \\
\hline
\end{tabular}

